NBER WORKING PAPER SERIES

\title{
THE CHANGING ASSOCIATION BETWEEN \\ PRENATAL PARTICIPATION IN WIC AND BIRTH OUTCOMES IN NEW YORK CITY
}

\author{
Ted Joyce \\ Diane Gibson \\ Silvie Colman \\ Working Paper 10796 \\ http://www.nber.org/papers/w10796
}
NATIONAL BUREAU OF ECONOMIC RESEARCH
1050 Massachusetts Avenue
Cambridge, MA 02138
September 2004

The views expressed herein are those of the author(s) and not necessarily those of the National Bureau of Economic Research.

(C2004 by Ted Joyce, Diane Gibson, and Silvie Colman. All rights reserved. Short sections of text, not to exceed two paragraphs, may be quoted without explicit permission provided that full credit, including () notice, is given to the source. 
The Changing Association Between Prenatal Participation in WIC and Birth Outcomes in New York City

Ted Joyce, Diane Gibson, and Silvie Colman

NBER Working Paper No. 10796

September 2004

JEL No. I12

\begin{abstract}
$\underline{\text { ABSTRACT }}$
We analyze the relationship between prenatal WIC participation and birth outcomes in New York City from 1988-2001. The analysis is unique for several reasons. First, we restrict the analysis to women on Medicaid and or WIC who have no previous live births and who initiate prenatal care within the first four months of pregnancy. Our goal is to lessen heterogeneity between WIC and nonWIC participants by limiting the sample to women who initiate prenatal care early and who have no experience with WIC from a previous pregnancy. Second, we focus on measures of fetal growth distinct from preterm birth, since there is little clinical support for a link between nutritional supplementation and premature delivery. Third, we analyze a large sub-sample of twin deliveries. Multifetal pregnancies increase the risk of anemia and fetal growth retardation and thus, may benefit more than singletons from nutritional supplementation. We find no relationship between prenatal WIC participation and measures of fetal growth except among a sub-sample of US-born Blacks between 1990-1992. A similarly sporadic pattern of association exists among US-born Black twins. Our finding that the modest association between WIC and fetal growth is limited to a specific racial and ethnic group during specific years and even specific ages suggests that the protective effect of prenatal WIC on adverse birth outcomes in New York City has been minimal.
\end{abstract}

Ted Joyce

Baruch Colege, CUNY and NBER

365 Fifth Avenue, 5th Floor

New York, NY 10016-4309

ted_joyce@baruc.cuny.edu
Diane Gibson

School of Public Affairs Baruch College, CUNY

One Bernard Baruch Way

New York, NY 10010
Silvie Colman

Department of Economics Graduate Center, CUNY

365 Fifth Avenue, $5^{\text {th }}$ Floor

New York, NY 10016 


\section{Introduction}

Over seven million women, infants and children participated in the Special Supplemental Nutrition Program for Women, Infants and Children (WIC) in 1999, up from 4.1 million in 1989. Over the same period expenditures in 1999 dollars grew from 2.6 to 4.0 billion dollars (U.S. House of Representatives 2000). A large body of published research suggests that prenatal participation in WIC increases birth weight and lowers the incidence of low and very low birth weight births. Based on the results from these studies, the General Accounting Office concluded that every federal dollar spent on prenatal WIC participants returned an estimated $\$ 3.50$ in savings in primarily reduced health care costs (General Accounting Office 1992). Since then, the general conclusion among policy makers has been that "WIC works."

In a recent review of previous research, however, Douglas Besharov and Peter Germanis (2001) challenge the widely held belief that WIC is a highly successful program. They contend that research on the association between WIC participation and improved birth outcomes suffers from outdated estimates and poor designs. Moreover, the results pertain to only 12 percent of WIC participants. At best, they conclude, WIC may have a small positive effect on birth outcomes of pregnant women at high risk for nutritional deficiencies.

In this study we use New York City birth certificates from 1988 to 2001 to address several of the concerns raised by Besharov and Germanis $(2000 ; 2001)$. For example, Besharov and Germanis argue that the composition of WIC participants has changed significantly over the past decade, which in turn may make earlier estimates of the effect of WIC on birth outcomes less relevant. The growth in WIC coincides with the expansion in Medicaid eligibility thresholds that occurred in the late 1980s and early 1990s. Women on Medical Assistance are automatically eligible for WIC, even if the income thresholds for Medicaid exceed those for 
WIC (Lewis and Ellwood 2000). As a result, the growth in WIC among pregnant women is likely to include proportionately fewer women at risk for adverse birth outcomes. With 14 years of data and almost 900,000 births to women on Medicaid in New York City, we examine the composition of women on Medicaid and WIC from the period before the Medicaid eligibility expansions through the most recent expansions for pregnant women under State Children's Health Insurance Program (SCHIP). We also test whether the association between WIC and birth outcomes has changed over time, and if so, whether the changing composition of participants can explain the difference.

The second contribution of our study is the focus on measures of fetal growth as outcomes by which to assess the effectiveness of WIC. Many previous studies have found large and statistically significant associations between WIC participation and very low birth weight births (VLBW $<1,500$ grams $(3.3 \mathrm{lbs}))$. Indeed, approximately two-thirds of the savings associated with WIC in the report by the General Accounting Office (GAO) resulted from a decrease in VLBW (GAO 1992). But such an association is highly implausible. Nationally, ninety-five percent of all VLBW births are preterm ( $<37$ weeks gestation) but only 10 percent of VLBW births are also small for gestational age. However, interventions to prevent preterm births remain elusive. An editorial in the New England Journal of Medicine summarizes clinicians' frustration,

"Trials measuring the effect of interventions at eliminating a single risk factor are numerous; uterine contractions have been suppressed, cervixes have been sewn shut, microorganisms have been eliminated, and social support, better nutrition, and prenatal care have been provided. When these factors have been studied in isolation, not one has resulted in a decline in preterm birth" (Iams, J. 1998, p. 54). 
If WIC is unlikely to affect the probability of a preterm birth, then the often-reported relationship between WIC and VLBW is highly suspect. We contend that measures of fetal growth are more appropriate outcomes by which to evaluate WIC.

Third, many studies report that improvements in birth outcomes associated with WIC are greater among women at medical risk such as smokers, teenagers and those with a previous premature delivery. Such results are interpreted as evidence that WIC is more beneficial for women in need of nutritional assistance. Even Besharov and Germanis $(2000 ; 2001)$ concede the possibility of such heterogeneous effects. However, these risk factors tend to be correlated with other hard to measure determinants of birth outcomes such as substance abuse, sexually transmitted disease, and stressful home environments. Thus, effects associated with WIC among a sample of women that smoke, for instance, may reflect greater unobserved heterogeneity between WIC and non-WIC participants than is found among lower-risk groups such as nonsmokers. As a cleaner test of whether the association between WIC and birth outcomes is greater among women at nutritional risk, we compare outcomes between WIC and non-WIC participants who deliver twins. Multiple gestations represent a random health shock that increases the risk of anemia, inadequate weight gain and adverse birth outcomes, but should be orthogonal to other risky behaviors. ${ }^{1}$

Finally, a universal concern among analysts of WIC has been selection bias. Do women that participate in WIC differ from non-participants in ways that are hard to measure but that are also correlated with the outcomes of interest? We take several approaches. In the first, we exploit our large sample size and stratify the analysis into more homogenous groupings. For

\footnotetext{
${ }^{1}$ An exception would be multiple gestations that resulted from assisted reproductive technology (ART). However, eighty-nine percent of women that receive ART are 30 years of age or older and 77 percent have no previous live births (Schieve et al. 2002). Women that receive such treatment are likely to be older, better educated and of zero or low parity---a group with a low probability of WIC participation.
} 
example, we analyze the association between WIC and fetal growth among foreign-born Hispanics on Medicaid, with no previous live births, all of whom who initiate prenatal care early. As an additional refinement, we use propensity score matching within strata and we drop cases in which there is not a common support between WIC to non-WIC participants. Propensity score matching does not solve the problem of selection on unobservable factors, but it may further improve the quality of our comparison group. Lastly, we estimate, but do not emphasize, estimates based on instrumental variables. We use New York State's Medicaid eligibility expansion in 1990 as an instrument for prenatal WIC participation.

\section{Background}

The conclusion that "WIC works" became conventional wisdom after the widely cited report by the GAO $(\mathrm{GAO}, 1992)$. Based on 17 studies, the GAO concluded that prenatal WIC participation lowered the rate of low birth weight (LBW $<2,500$ grams $(5.5 \mathrm{lbs})$ ) by 25 percent and the rate of very low birth weight by 44 percent. These improvements in newborn health generated immediate savings of $\$ 2.89$ per dollar invested in WIC in the first year of life and $\$ 3.50$ in savings if estimated over 18 years. Five of the 17 studies were based on the influential analysis conducted by researchers at the Mathematica Policy Research, Inc. In that study, researchers linked birth certificates to WIC administrative files in 1987 and 1988 in five states: Florida, Minnesota, North Carolina, South Carolina and Texas (Devaney, Bilheimer and Schore 1992). Researchers reported that mean birth weight was 87 grams greater and the incidence of low birth weight was 3.8 percentage points less among WIC relative to non-WIC participants.

Similar results based on equivalent methods were obtained from a national sample of births in1988 from the National Maternal and Infant Health Survey (NMIHS). The NMIHS is a 
national sample drawn from natality files with more extensive information on maternal characteristics and behaviors than was available from state-specific linkages of administrative data to birth certificates (Gordon and Nelson 1995). The national sample increased the generalizability of the findings and the additional covariates lessened the potential of omitted variable bias.

\section{Appropriate Outcomes}

An important consideration when evaluating the findings of the previous research on WIC is whether there is a plausible mechanism for the relationship between WIC and the outcome of interest. Most studies have emphasized the association between WIC and the probability of a low birth weight birth. However, low birth weight can be broadly divided between preterm births - those that occur before the $37^{\text {th }}$ week of gestation — and those that are small for gestation age (SGA). The latter is an indication of fetal growth retardation. As noted above, the causes of preterm birth are largely unknown and few interventions, if any, appear effective. Thus, the incidence of very low birth weight, 95 percent of which are preterm, would seem an inappropriate outcome with which to assess the effectiveness of nutritional education or supplementation. ${ }^{2}$ A stronger case can be made for an association between fetal growth retardation and prenatal supplementation, since the latter is more closely linked to nutritional intake and maternal weight gain (Institute of Medicine 1990).

There is little doubt, for instance, that extreme nutritional deprivation in the prenatal period affects fetal growth. The Dutch Famine of 1944-45, for example, was associated with a 300 gram decrease in mean birth weight (Stein and Susser 1975). However, the association

\footnotetext{
${ }^{2}$ Indeed, in the Dutch Famine study, severe nutritional deprivation had a major effect on birth weight but was unassociated with gestational age.
} 
between nutritional supplementation and birth weight in developed countries is less clear. In a randomized trial of poor women in New York City, there was some evidence that prenatal supplementation increased maternal weight gain, but supplementation was unrelated to birth weight (Rush, Stein and Susser 1980). Similarly, in the National WIC Evaluation researchers found no association between WIC participation and birth weight, despite significant increases in the intakes of 4 out of the 5 nutrients that were analyzed (Rush et al. 1998). And in the only randomized trial of WIC participation, researchers found no effect of WIC participation on birth weight except for among a subset of maternal smokers (Metcoff et al. 1985).

Importantly, studies that show an association between WIC and low birth weight or mean birth weight report statistically insignificant associations or small effects of WIC on proxies for fetal growth. In the Mathematica study, differences in mean birth weight fall from 87 grams averaged across the five states to 25 grams when gestational age is included in the birth weight specification (Devaney, Bilheimer and Schore 1992 ). The same is true in a detailed assessment of WIC based on the NMIHS. A statistically significant mean difference in birth weight of 68 grams falls to a statistically insignificant difference of 25 grams when adjusted for gestational age (Gordon and Nelson 1996). Kotelchuck et al. (1984) find that participation in WIC in Massachusetts is associated with a 1.8 percentage point decline in low birth weight, but WIC is not associated with infants that are small for gestational age (SGA), a standard indicator of fetal growth retardation. Stockbauer (1987) and Buescher and Horton (2000) obtain similar results in Missouri and North Carolina respectively. In none of these analyses, however, do the authors interpret the lack of a substantive association between WIC and fetal growth as inconsistent with the inference that WIC improves infant health. Instead, researchers conclude that WIC has a strong indirect effect on birth weight or low birth weight through prolonged gestation. 
The recent paper by Bitler and Currie (2003) is a case in point. The authors use the Pregnancy Risk Assessment Monitoring System (PRAMS) to analyze the association between prenatal WIC participation and a host of birth outcomes. PRAMS links a postpartum survey of recent mothers with information from the birth certificate. The authors use an unbalanced panel of 19 states from 1992 to 1999 . The sample contains information on over 60,000 birth outcomes to women on Medicaid, 49,000 of which participated in WIC. They find that WIC is associated with a 54 percent decrease in the odds of a very low birth weight birth and a 53 percent decrease in the odds of very premature infants ( $<32$ weeks gestation). Effects for teens are substantially larger. Since both outcomes are rare the coefficients can be interpreted as changes in the relative risk, which suggests that WIC lowers the probability of extreme prematurity by more than half for all women on WIC and by two-thirds for teens. Such effects are implausible given that prenatal interventions reported in the clinical literature have not been effective at preventing preterm birth (Goldenberg and Rouse 1998). ${ }^{3}$

Significantly, Bitler and Currie (forthcoming) also find that WIC is associated with only a 13 percent decline in the odds that a newborn is small for gestational age (SGA); moreover, the coefficient is statistically insignificant in two of the three high-risk subgroups that they analyze separately. They also report that WIC is associated with an increase of slightly over a pound in maternal weight gain during pregnancy, which provides some corroboration for the modest increase in fetal growth.

\footnotetext{
${ }^{3}$ See also Dyson et al. 1998 and the Collaborative Group on Preterm Birth Prevention (1993) for trials to prevent preterm birth.
} 


\section{Selection Bias}

An additional concern with previous research on WIC is that the estimates of the effect of WIC are subject to selection bias. A number of approaches such as the use of statistical controls, matched samples or instrumental variables have been used to attempt to minimize this bias, but none of them are ideal. Selection bias occurs if women that participate in WIC are more motivated to deliver a healthy baby or more risk averse than their counterparts who choose not to participate. If motivation or risk aversion is negatively correlated with other hard to measure factors that increase the risk of preterm delivery or fetal growth retardation (i.e, the intensity of smoking, illegal drug use, vaginal infection), then omitted variable bias will cause the estimated effect of WIC to be overstated. There has been only one randomized trial involving WIC and results were equivocal (Metcoff et al. 1985).

In most observational studies researchers use statistical controls or matched samples to lessen contamination from selection bias. One criticism is that the set of covariates from administrative data and birth certificates is limited, which makes inferences vulnerable to omitted variable bias (Devaney, Bilheimer and Schore 1992; Schramm 1985; 1986; Stockbauer 1986; Stockbauer 1987; Kotelchuck et al. 1984). Studies with much more detailed information on maternal behavior and socio-economic status have obtained similar findings to studies with many fewer covariates (Gordon and Nelson 1996; Bitler and Currie forthcoming). However, even the use of detailed covariates may not be adequate to deal with selection bias.

Studies that match pregnant women on WIC to eligible pregnant women on waiting lists for WIC or to women in counties without WIC programs have reported mixed results. Women who applied for WIC in Massachusetts, but who were not certified due to a lack of openings, had infants with lower mean birth weights than infants of women enrolled in WIC (Kennedy et al. 
1982). An alternative matching strategy has been to use two births to the same woman. During one pregnancy the mother participated in WIC and in the other she did not (Kowaleski-Jones and Duncan 2002). The advantage of models with "individual fixed effects" is that they remove confounding from time-invariant characteristics of the mother. Yet, at the same time they raise the question of why a woman participated in WIC once and not again. If she became ineligible because of an increase in income, or was not at nutritional risk, then potential problems of selection bias are re-introduced if these other changes are not adequately controlled. Finally, sample sizes tend to be small and arguably unrepresentative. In the study by Kowaleski-Jones and Duncan (2002), the estimated effects of WIC on birth weight are very large, but are based on the experience of only 71 women whose experience with WIC varied between pregnancies.

Econometric approaches to selection bias have yielded highly unstable results due to the lack of a credible identification strategy (Fraker et al. 1995; Brien and Swann 1999). Researchers have yet to find a variable that predicts WIC participation, but that has no direct effect on birth outcomes. Brien and Swann (1999), for instance, use indicators of WIC clinics, AFDC guarantees and Medicaid expenditures per family to predict WIC participation.

However, they do not include state fixed effects and thus rely on between-state variation in social policies to identify WIC participation. The exogeneity of the instruments is not convincing since differences in social policy across states may reflect unmeasured state-level factors that affect infant health.

Selection or omitted variable bias may also be exacerbated by the common practice of obtaining separate estimates of the effect of WIC on infant health for women with elevated risks of adverse birth outcomes (Kennedy and Kotelchuck 1984; Stockbauer 1986,1987; Schramm 1985, 1986; Buescher et al. 1993). The empirical strategy is based on WIC eligibility criteria 
that use characteristics such as smoking, teen pregnancy, short birth spacing and high parity as markers for nutritional risk (Institute of Medicine 1996). Many researchers have reported, for example, that differences in mean birth weight between WIC and non-WIC smokers are greater than between nonsmokers or between WIC and non-WIC women more generally (Metcoff et al. 1985; Schramm 1985,1986; Stockbauer 1986). This is interpreted as evidence that women with greater "nutritional" need benefit more from WIC than women with less need. But differences between WIC and non-WIC participants that smoke may simply reflect differences in actual smoking intensity or differences in other unobserved behaviors that are correlated with smoking and not heterogeneous treatment effects.

In summary, there are many concerns with the previous research on WIC. With few exceptions, studies pertain to women who gave birth in the 1970s and 1980s, but a doubling of WIC enrollment over the past 12 years undermines the relevancy of these earlier studies. In addition, some of the outcomes used to evaluate WIC lack a clinical link to nutritional supplementation. Finally, selection bias remains a threat to the validity of received work and the conclusion that WIC is more effective among women at elevated risks of adverse birth outcomes may be a further manifestation of omitted variables bias. In this study we present the first attempt to look at the average treatment effect of WIC over time. We use proxies for fetal growth and maternal weight gain as outcomes and we take two approaches to limit contamination from selection bias. Finally, we present results from an analysis of WIC and fetal growth among 11,000 twins as a test of whether WIC has a greater association among infants of women with exogenous increases in the risk of anemia, inadequate weight gain and intrauterine growth retardation. 


\section{Data}

We analyze the relationship between prenatal WIC participation and birth outcomes in New York City from 1988-2001 women on Medicaid and/or WIC as recorded on birth certificates. New York City is a separate vital registration area. Its birth certificate is arguably the most detailed in the country. Since 1988 it has included the method of finance (Medicaid, other third party, HMO, and self pay) and whether the mother was enrolled in WIC during pregnancy. There are also indicators of smoking, illicit drug use, as well as the standard set of socio-demographic characteristics of the mother available from all birth certificates.

The indication of WIC participation is a dichotomous variable. Thus, we lack information on how long the mother has been enrolled or when she enrolled during pregnancy. We are also concerned about accuracy of the indicator given that it is largely self-reported. To investigate the quality of the data, we compare the proportion of women on WIC in New York City as obtained from birth certificates to other sources with similar information. We summarize the results in Table 1. The most significant and convincing comparison comes from a 1990 analysis conducted by the New York State Department of Health (1990). Researchers for the State linked the WIC History File to New York State birth certificates in 1988. The match rate was 96 percent. This matched file was then linked to the state hospital discharge data set (SPARCS). Summary statistics are presented for New York City and Upstate New York. As shown in Table 1, the State reported that 21.3 percent of births to New York City residents in 1988 were enrolled in WIC during pregnancy. The figure from the New York City birth certificate was 21.0 percent. As an additional check we compared data from two other sources: the 1988 National Maternal and Infant Health Survey or NMIHS (http://www.cdc.gov/nchs/products/elec_prods/subject/mihs.htm) and 1993 Pregnancy Risk 
Assessment Monitoring System or PRAMS (http://www.cdc.gov/nccdphp/drh/srv_prams.htm).

NMIHS does not identify the state of residence on the public use file and thus we compared New York City to the northeast region. Similarly, the PRAMS data from New York does not include births to women from New York City. Although PRAMS does not include births for New York City, we used the City and Upstate distribution of WIC participation in 1988 and the total figure for upstate New York State in 1993 to approximate participation in New York City. As is evident from Table 1, WIC participation based on New York City birth certificates is consistent with other surveys.

Finally, WIC is not an entitlement program. If demand for WIC exceeds the allocated funds, then eligible candidates may not receive benefits. Pregnant women, however, are among the eligible groups with the highest priority for WIC services and the prenatal WIC program has been fully funded in New York State over the study period. ${ }^{4}$

\section{Outcomes}

We present results for birth weight and low birth weight so that our results can be compared to previous work. We use the standard definition of low birth weight, which is infants born less than 2500 grams. We use three measures of fetal growth. The first is birth weight adjusted for gestational age. The second measure is a dichotomous indicator of infants below the 10th percentile in weight for gestation based on all singleton births to US residents in 1995 (Alexander et al. 1998). They are referred to as small for gestational age (SGA). Our final measure of fetal growth is an indicator of infants that are term, low birth weight $(>36$ weeks gestation and $<2500$ grams).

\footnotetext{
${ }^{4}$ Personal communication: Roberta Hayward, Division of Nutrition, Bureau of Supplemental Food Programs, New York State Department of Health. It is more difficult to determine whether nutritional counseling has changed over time. Moreover, the only change in New York State in the availability of food that we were able to establish was the
} 
We use maternal weight and net maternal weight gain during pregnancy as intermediate outcomes that may be related to nutritional supplementation. Net maternal weight gain is total weight gain less the weight of the newborn. Net maternal weight gain removes spurious association related to what epidemiologists refer to as part-whole correlation (Institute of Medicine 1996). However, weight gain is not reported consistently over time in our data. In 1988-90, for example, weight gain was unknown for 27 percent of WIC participants but 67 percent of non-WIC participants with no previous live births and who initiated prenatal care in the first four months of pregnancy (see Table 2). By 1999-2001, the percent unknown had fallen to approximately six and nine percent, respectively. Thus, for maternal weight gain during pregnancy, we limit the analysis to 1999-2001.

\section{Analysis of twins}

A novel aspect of this study is a subset of analyses based on the outcomes of multifetal pregnancies that result in twins. There were over 40,000 deliveries to twins in New York City between 1988 to 2001, of which approximately 11,000 were to women on Medicaid and/or WIC. Thus, we analyze the association between WIC participation and birth outcomes to women on Medicaid or on WIC without Medicaid who delivered twins over the study period. Although twin deliveries represent less than two percent of all live births, the rate of low birth weight is over 50 percent among twins in the United States as compared to 6 percent for singletons. Women pregnant with twins have 2.4 times the risk of anemia and the American College of Obstetrics and Gynecology (ACOG) recommends that women carrying twins consume $300 \mathrm{Kcal}$ per day above that recommended for singletons (Gall 1996; ACOG 1999). WIC programs in all

1989 Farmers' Market Nutrition Program (FMNP). The program provided coupons for fresh fruits and vegetables to WIC participants. 
51 states consider multifetal gestations a marker for women at nutritional risk (Institute of Medicine 1996).

\section{Empirical Methods}

Analysis of singleton births

The composition of women that gave birth in New York City has changed significantly over the 14 years of our study period. In 1988, for example, 39.0 percent of all births in the City were financed by Medicaid as compared to 55.8 percent in 2001. Similarly, the percent of births to foreign-born women increased from 40.1 in 1988 to but 53.0 percent in 2001. To adjust for such shifts in the distribution of births by maternal characteristics, we estimate regressions of the form:

$$
\mathrm{G}_{\mathrm{it}}=\alpha_{0}+\alpha_{1} \mathrm{WIC}_{\mathrm{it}}+\mathbf{x}_{\text {it }}^{\prime} \boldsymbol{\beta}+\sum y r_{t}+\mathrm{e}_{\mathrm{it}}
$$

Let $\mathrm{G}_{\mathrm{it}}$ be the fetal growth in grams adjusted for gestational age of infant $\mathrm{i}$ in year $\mathrm{t}$; let $\mathrm{WIC}_{\mathrm{it}}$ be one if the mother participated in WIC during pregnancy in year $\mathrm{t}$, let $\mathbf{x}_{\mathrm{it}}$ be a vector of maternal characteristics and let $\mathrm{yr}_{\mathrm{t}}$ be an indicator of the year. The coefficient on WIC, $\alpha_{1}$, estimates the average treatment effect of WIC on fetal growth under two assumptions: first, that the decision to participate in WIC, conditional on $\mathbf{X}$, is uncorrelated with fetal growth in the absence of participation; and second, that the expected gains to participation are constant across individuals (Heckman 1997; Wooldridge 2002). Both assumptions are clearly strong. To illustrate, Figures 1 and 2 show the rate of low birth weight births and mean birth weight, respectively, for singleton births to women on Medicaid by WIC and non-WIC participants in New York City from 1988 to 2001. In 1988, the difference in the rate of low birth weight 
between WIC and non-WIC participants was 3.5 percentage points and differences in mean birth weight was 95 grams. Both estimates are quite consistent with much of the literature of the 1980s. As is apparent in both Figures, however, mean differences diminish overtime. There are also large differences by race, ethnicity and nativity, as we show below. Consequently, we interact WIC with the year dummies and we estimate separate models by race, ethnicity and nativity. With these specifications the assumption of constant average treatment effects may be less problematic, since it pertains to more homogenous groups at a specific point in time.

The other key assumption is that WIC participation is uncorrelated with fetal growth in the absence of participation. In other words, do women select into WIC because they have strong preferences for health and are highly risk averse (favorable selection); or, is the opposite true: women that participate in WIC have underlying health problems that are not observed by researchers (adverse selection). We take two approaches to mitigate selection bias. First, we estimate models that are limited to women of zero parity who initiate prenatal care in the first four months of pregnancy, a standard definition of early prenatal care (Kotelchuck 1994). The idea is to compare outcomes among a sample of women whose preferences, motivation, and experience with pregnancy are similar. For example, data from the NMIHS indicate that in 1988, 67 percent of prenatal WIC participants who had at least one previous live birth had been enrolled in WIC during a preceding pregnancy (Gordon and Nelson 1995). Women previously enrolled in WIC may be more likely to register for early prenatal care. They may be better informed about nutrition and other risk factors and have stronger preferences for healthy behavior. By restricting the sample to women with no previous live births, we eliminate the possibility of differential experience with WIC between current participants and nonparticipants. Similarly, early prenatal care may be another marker for favorable selection. The 
first prenatal care visit is initiated by the woman. Subsequent visits may be in response to the prenatal protocol. Thus, the timing of the first visit as opposed to an index of prenatal care may better reflect a mother's attitude and access to prenatal care.

To illustrate the difference in risk factors by the timing of prenatal care in our sample, we display the percent of births exposed to cocaine or heroin from 1988 to 2001 . We also display these differences by race, ethnicity and nativity. Figure 3 pertains to women on Medicaid and or WIC who initiated prenatal care in the first-four months of pregnancy. Figure 4 shows the same series but for women who initiated prenatal care late. We stratify the four series in each figure by WIC and non-WIC participants. Two observations are salient. First, differences in exposure by nativity are huge. Foreign-born women, and in particular Hispanics, have very low rates of exposure to illicit drugs regardless of when they begin prenatal care. ${ }^{5}$ Second, differences in exposure vary by year, WIC participation, and the timing of prenatal care among U.S. born blacks. Exposure is greatest between 1988-90, roughly the peak years of the crack/cocaine epidemic in New York City, and it declines substantially by 2001. Given these patterns, we hope to lessen heterogeneity between WIC and non-WIC participants by estimating separate models by race, ethnicity, nativity, parity and the timing of prenatal care.

An important limitation of our identification strategy is that our results will only generalize to primaparas who initiate prenatal care early. We consider this an acceptable tradeoff. The danger of omitted variable bias in program evaluation with observational data is clearly profound. The strength of our analysis is the large number of observations over a 14-year period. This allows us to define relatively homogenous groups and to test whether treatment effects vary over time. If the composition of our samples is constant over the study period

\footnotetext{
${ }^{5}$ This is not specific to New York City. Vega et al. (1993) analyzed the urine of over 29,000 women who delivered in California in 1992 and found similar differences by race and ethnicity.
} 
(based on observables), then time-varying treatment effects would be consistent with some form of selection into WIC.

We take two other approaches to estimate the association between WIC and birth outcomes. We use propensity score matching with the selected sample of first births to women who begin care early. We use nearest neighbor matching after balancing characteristics between WIC and non-WIC participants by blocks of propensity scores. We also drop observations that lack a common region of support (Becker and Ichino 2002). We appreciate that neither stratification nor matching guarantees that selection bias is minimized. Thus, we also obtain estimates based on instrumental variables (IV). The results from propensity score matching and IV models are presented in Appendix II. The estimates obtained by propensity score matching differed little from those obtained by OLS. The IV estimates of the relationship between WIC and fetal growth outcomes are not significant. However, we choose not to focus on these results because the variables we use as instruments are not ideal. We present a fuller discussion of these results in Appendix II.

\section{Analysis of Twins}

As noted above, researchers often estimate equation (1) separately for groups at greater "nutritional" risk, such as smokers and teens. The objective is to allow for interactions between need and participation. To illustrate, we re-write equation (1) and drop the vector of covariates 
and time dummies to simplify notation.

$$
\mathrm{G}_{\mathrm{it}}=\alpha_{0}+\alpha_{1} \mathrm{WIC}_{\mathrm{it}}+\alpha_{2} \delta_{\mathrm{it}}+\alpha_{3}\left(\mathrm{WIC} * \delta_{\mathrm{it}}\right)+\pi_{\mathrm{it}}+\mathrm{e}_{\mathrm{it}}
$$

let $\delta_{\text {it }}$ be a measure of nutritional risk. Common measures of nutritional risk $\left(\delta_{i t}\right)$ include smoking, teen pregnancy and high parity. Let $\pi_{\mathrm{it}}$ be unobserved behaviors related to adverse birth outcomes such as heavy smoking, illicit drugs and risky sex that increases exposure to sexually transmitted disease. Estimates based on equation (2) are likely to exacerbate problems of omitted variables since characteristics of nutritional risk $\left(\delta_{\mathrm{it}}\right)$ are likely correlated with $\pi_{\mathrm{it}}$.

The use of twins as a measure of $\delta_{\text {it }}$ offers two advantages to previous measures of nutritional risk. First, multifetal pregnancies increase the risk of anemia and fetal growth retardation, conditions that should be more sensitive to nutritional supplementation than preterm birth. Second, twinning is randomly assigned and thus unlike smoking, for example, twinning should be orthogonal to other risky behaviors $\left(\pi_{\mathrm{it}}\right)$. Thus, a comparison of outcomes between WIC and non-WIC participants all of whom delivered twins should be a more legitimate test of whether WIC has a greater effect among women at increased nutritional risk.

One potential weakness in this design is that some women may enroll in WIC after the diagnosis of multiple pregnancies. Thus, even if twinning is orthogonal to $\pi_{\text {it }}$ prior to diagnosis, women with stronger preferences for health, higher motivation, or who are more knowledgeable may seek out WIC in response to their condition, a form of favorable selection. In an attempt to lessen such selection, we limit the sample to women who initiate prenatal care in the first four months of pregnancy. As with the analysis of singleton births, the idea is to restrict the analysis to a sub-sample of women with similar motivation and access as reflected in their prompt 
initiation of prenatal care. We do not stratify initially by previous live births because of possible recording errors in the measure of parity among twin deliveries. ${ }^{6}$

Another concern is that the exogeneity of twinning will be compromised if multifetal conceptions resulted from assisted reproductive technologies (ART). Women who use ART are likely to be highly motivated about achieving a healthy birth outcome and may self select into WIC. Age and year of birth, however, are important correlates of ART and twinning (Ventura et al. 1999). Eighty-nine percent of women that receive ART in 1996-1997 were 30 years of age or older and the number of infertility clinics and the use of ART have also grown rapidly over time (Schieve et al. 2002; Jain, Missmer and Hornstein 2004). To lessen the potential bias from women who use ART, we re-estimate the models for twins and limited the sample to women less than 30. We also allow the effect of WIC to vary by year since the impact of ART should be less in the late 1980s and early 1990s.

\section{Results}

\section{Singleton births}

Summary statistics for WIC and non-WIC participants are displayed in Table 2 at three points in time: 1988-90, the period roughly prior to the Medicaid expansion in New York State, the years 1994-1996, the years prior to welfare reform and then 1999-2001. Our sample in Table 2 includes only singleton first births to women on Medicaid or on WIC without Medicaid participation who initiate prenatal care in the first four months of pregnancy. Differences in

\footnotetext{
${ }^{6}$ The birth certificate indicates which twin is the first. If a woman had no previous live births, then parity for the first twin should be zero and the second twin should have a parity of one. This appears correct for approximately 80 percent of twin deliveries, except in 1994 and 1995 in which it is only true for 20 percent of deliveries. In our sensitivity analysis we do the following: we assume all twins with the same parity of zero, regardless of which twin was delivered first, are parity zero. We then combine these with the consistent indications of parity zero and reestimate the models for twins whose mothers initiate care early and who have no previous live births.
} 
birth outcomes by WIC participation are qualitatively consistent with the literature between 1988-1990, but of a smaller magnitude. There are statistically significant differences in mean birth weight (28 grams), low birth weight (1.3 percentage points), preterm birth (1.8 percentage points) and infants that are small for gestational age ( 0.7 percentage points). The characteristics of women in WIC between 1988-90 are marginally more favorable with respect to education, prenatal care visits and illicit drug use than their non-WIC counterparts. By 1994-1996 there are no meaningful differences in birth outcomes and women in WIC are now more disadvantaged, albeit modestly, than their non-WIC counterparts with respect to education, marital status and teen motherhood. These modest disadvantages increase slightly by 1999-2001.

However, the racial and ethnic distribution of WIC and non-WIC participants change more substantially over the study period. For instance, the proportion of births to Asians on Medicaid but not on WIC rises from 3.6 percent in 1988-1990 to 25.8 percent in 1999-2001 while the proportion of Puerto Ricans and Black non-Hispanics falls 9.5 and 17.8 percentage points respectively. The racial and ethnic composition among WIC participants changes similarly, but not as dramatically. These shifts would appear responsible in part for the narrowing of birth outcomes between WIC and non-WIC participants as displayed in Figure 1, since Asians and other Hispanics have lower rates of adverse birth outcomes than do Puerto Ricans and non-Hispanic Blacks. Thus Besharov and Germanis were correct that the Medicaid eligibility expansions altered the distribution of characteristics among WIC and non-WIC participants in New York City. Yet dichotomous controls for race and ethnicity might not adequately control for the myriad of differences among these groups and their possible interactions with observed characteristics. This is a major reason why we stratify our analyses by race, ethnicity and nativity. 


\section{Multivariate analysis}

In order to provide a point of comparison with previous research, we start our analysis with a consideration of the relationship between WIC and birth weight. We also explore how the use of one of our main sub-samples of interest (first time mothers with singleton births who initiated prenatal care early) may influence these results.

The first column of Table 3 presents mean differences in birth weight between WIC and non-WIC Medicaid participants with singleton births unadjusted for any covariates as shown in Table 3. We then show the estimates of $\alpha_{1}$ in equation (1) followed by estimates of the interaction between WIC and the year dummies. The last two columns in Table 3 display estimates for the sub-sample of women who initiate prenatal care early and who have no previous live births. The unadjusted difference in mean birth weight between WIC and non-WIC participants is 46 grams over the 14 years of the sample. After adjustment, mean differences fall by 44 percent to 25.9 grams. However, among women who initiate care early, mean differences are smaller still at 18.0 grams, and if we restrict the analysis to those who begin care early and who have had no previous live births, and thus no experience with WIC, adjusted mean differences fall to 10.5 grams.

The same pattern persists across specifications when we allow average treatment effects to vary by year. The adjusted estimate for 1988 among all women, 55 grams, is broadly consistent with the literature (Devaney, Bilheimer and Schore 1992). Other researchers have also found that average treatment effects are smaller for women who enrolled in WIC earlier in pregnancy (Devaney, Bilheimer and Schore 1992; Gordon and Nelson 1996).

One interpretation of the results in Table 3 is that the treatment effects associated with WIC are small or inconsequential among men who begin care early and who have no previous 
live births. These women are arguably the most homogenous group available from these data and thus, provide the least contaminated test of WIC. An alternative interpretation is that women who present for prenatal care early in pregnancy are the least likely to need nutritional supplementation and thus the gains to WIC are expected to be less. The diminution of effects over time, however, regardless of the sample, suggests that problems of omitted variables persist. As demonstrated in Table 2 there has been a significant change in the composition of women both on Medicaid and WIC. And despite the inclusion of controls for race and ethnicity, there could be important interaction effects for which we do not account. We turn, therefore, to the next set of analyses in which we stratify by race, ethnicity and nativity.

Table 4 presents regression estimates of equation (1 ) for all women on WIC or Medicaid, who initiated prenatal care early and who had no previous live births. There are six birth outcomes. The first three pertain to various measures of birth weight; the second set contains proxies for fetal growth, outcomes that we contend are more appropriate for assessing the effect of nutritional supplementation and counseling. As before, we first show estimates for all years and then estimates from the interaction of WIC and year.

There is modest evidence at best of an association between WIC and measures related to birth weight. Moreover, the statistically significant results that do exist are limited to the late 1980s and early 1990s. There is little association between WIC and measures of fetal growth. For instance, the coefficients on WIC in the regression of birth weight adjusted for gestational age are either small and statistically insignificant or they have the wrong sign. In other words, the positive association between WIC and birth weight reflects prolonged gestation. The same point is made if we compare estimates from the regression of low birth weight on WIC with the regression estimates from term low birth weight on WIC. In the few years in which there is a 
significant association between WIC and low birth weight, there is no equivalent relationship for term low birth weight. The association between WIC and low birth weight, therefore, is driven by the correlation between WIC and preterm birth, an association for which there is little clinical support. The third measure of fetal growth pertains to infants born small for gestational age (SGA). The coefficient on WIC averaged across all years has the wrong sign (0.003) and is statistically insignificant.

To further explore the question of omitted variables bias, we re-run the regressions in Table 4 for two subgroups: US-born non-Hispanic blacks and foreign-born Hispanics. One objective is to lessen heterogeneity due to the changing composition of WIC participants over time. In addition, the two groups had very different exposure to crack cocaine. Numerous studies of prenatal cocaine use have documented much higher prevalence among blacks than Hispanics and among US-born as compared to foreign-born women. ${ }^{7}$ Figure 3 shows a similar pattern. If differential exposure to cocaine in the early years of our study period is driving the results, we would expect to see larger differences in birth outcomes by WIC for US-born Blacks than for all women. The opposite should occur among foreign-born Hispanics.

Regression estimates for US-born Blacks and foreign-born Hispanics are shown in Tables 5 and 6, respectively. Again the sample pertains to only Medicaid or WIC recipients who initiate prenatal care in the first four months of pregnancy and who have no previous live births. For US-born Blacks there are large and statistically significant differences in rates of low birth weight in 1988-1991 by WIC (Table 5). On average, WIC participants are 2.7 percentage points less likely to experience a low birth weight birth over this period. After 1991, the average

\footnotetext{
${ }^{7}$ In the largest prevalence study of prenatal exposure to illicit substances ever undertaken, researchers in California tested the urine of almost 30,000 mothers at delivery in 1992. Seven and a half percent of all blacks tested positive for cocaine whereas only 0.5 percent of Hispanics. Important differences by nativity have also been demonstrated.
} 
difference falls and in only three of the 10 subsequent years are differences statistically significant. Importantly, however, there are few statistically significant differences in fetal growth between WIC and non-WIC participants. A comparison of the treatment effects between WIC and low birth weight with those of WIC and term low birth weight again suggests that the association between WIC and low birth weight reflects primarily an association between WIC and preterm birth.

The results for foreign-born Hispanics provide an important point of contrast to those of US-born Blacks. As shown in Table 6 there is only one statistically significant coefficient with the expected sign out of a possible set of 84 . Nor is the result due to a lack of power. Few of the coefficients are of a clinically meaningful magnitude.

We draw two tentative conclusions from this exercise. First, if we lessen confounding from compositional changes in WIC participants by looking within race, ethnicity and nativity, we find little evidence of any substantive association between prenatal WIC participation and fetal growth over the study period. Second, there are relatively large differences in low birth weight between WIC and non-WIC participants among US-born Blacks but not among foreignborn Hispanics. Moreover, the differences are largely concentrated between 1988-1992. The pattern of results is consistent with the interpretation that unobserved heterogeneity related to crack-cocaine epidemic, and not treatment effects associated with WIC, is the most plausible explanation for the association between WIC and low birth weight. This is difficult to prove, since information on exposure is undoubtedly underreported on birth certificates. Nevertheless, relative differences in exposure to cocaine and heroin by race, ethnicity and nativity as shown in 
Figures 3 and 4 and from rigorous studies of prenatal exposure (Vega et al. 1993) are consistent with this interpretation.

\section{Analysis of Twins}

The notion that WIC should have a greater impact among women at greater nutritional risk remains an important rationale for the existence of supplemental nutrition and nutritional counseling. In this section we present results of the association between WIC and birth outcomes for a sample of twins. As before, the sample is limited to all women on WIC and or Medicaid who initiated prenatal care in the first four months of pregnancy. Summary statistics by WIC are presented in Appendix I, Table IA. As is immediately apparent, the rate of adverse birth outcomes is much greater among twins than singletons. Fifty-seven percent of twins not on WIC are low birth weight as compared to 52 percent for those on WIC in 1988-90. By 199901, differences in low birth by WIC have reversed. The same is true for SGA. Note that we include two measures of SGA. The first uses a singleton norm (SGA-S) and the other uses norms for all US born twins (SAG-T) in 1995 (Alexander et al. 1998). ${ }^{8}$

As with singletons, the composition of women on Medicaid and or WIC who delivered twins changed over the sample period. By 1999-2001 WIC and non-WIC participants have more education, more prenatal care visits, smoke less and are more likely to be foreign-born than their counterparts in 1988-1990. However, the improvements are relatively greater among non-WIC participants.

In Table 7 we show adjusted mean differences in birth outcomes by WIC for the sample of twins obtained from the estimation of equation (1). We present estimates for the entire 14- 
year period and then separately by various years. As before, we analyze three samples: all women, US-born Blacks and foreign-born Hispanics. The pattern of results for all women and foreign-born Hispanics largely reflects those of singletons. We show a modest association between WIC participation and infants that are small for gestational age among all women, but no association with birth weight adjusted for gestation or term low birth weight. There is no association between WIC and fetal growth among foreign-born Hispanics. For US-born Blacks, we find that WIC is associated with an increase of 55 grams in birth weight adjusted for gestation and a decline of 3.9 percentage points in the rate of SGA $(p<.01)$. The effects are concentrated in the 1993-1997 period.

We next allow estimates to vary by the age of the mother (Table 8). We are concerned that estimates for older women may be contaminated by self-selection associated with assisted reproductive technologies. A notable finding is that WIC participation is related to birth weight adjusted for gestational age and term low birth weight among US-born Blacks 24 years of age or less. For US-born Blacks 30 years of age or older, the pattern of results across the fetal growth outcomes is less consistent with an effect of WIC. There is little evidence that WIC is effective among all women and the subgroup of foreign-born Hispanics. As a further check of the results, we limited the sample to first birth twins based on our algorithm described earlier and reestimated the results in Tables 7 and 8. The results for young black women become somewhat stronger (available upon request). Overall, the exercise based on twins suggests that the association between WIC and fetal growth is limited to US-born black women less than 25 years of age.

\footnotetext{
${ }^{8}$ SGA-T classifies a birth as small for gestational age if the infant is below the 10 percentile of weight for gestation based on all twin deliveries in the US in 1995. The rationale for a separate standard for twins is based on their
} 


\section{Specification checks}

We have included in our analyses the sub-sample of women who participated in WIC but who were not on Medicaid. We are concerned that women on WIC but not on Medicaid may differ in unobserved ways that are associated with birth outcomes, especially before 1990 when income eligibility thresholds for WIC were higher than Medicaid. We dropped these women, and re-estimated the models in Table 4-6. The results changed inconsequentially (available upon request).

Another limitation of the analysis to this point has been the omission of information on pre-pregnancy weight and maternal weight gain during pregnancy. As noted previously, there is a large proportion of missing data for these variables in the early and middle years of the study period. Reporting improves significantly after 1998 (see Table 2). Thus, we re-estimated equation (1) the years 1999-2001 with pre-pregnancy weight included. We continue to find no association between WIC and fetal growth for all women including US-born Blacks with and without pre-pregnancy weight included. We also regressed maternal weight gain during pregnancy and net weight gain on WIC and pregnancy weight. The coefficient on WIC generally had the wrong sign (negative) and was relatively small in magnitude (less than half a pound). The results for weight gain are consistent with the lack of any meaningful association between WIC and fetal growth among singletons. ${ }^{9}$

\footnotetext{
greater rates of birth-weight specific survival.
}

${ }^{9}$ Results are available upon request. 


\section{Conclusion}

We use New York City birth certificates from 1988 to 2001 to analyze the association between prenatal participation in WIC and birth outcomes. If we limit the analysis to the years 1988-1990, our results are consistent with much of the literature. We find that WIC participants have lower rates of low birth weight and greater mean birth weights than non-participants. However, upon further analysis we find that differences in birth outcomes between WIC and non-WIC participants are not uniform across race and ethnicity, pertained primarily to differences in preterm birth and not fetal growth, and become inconsequential and statistically insignificant over time. Moreover, with the exception of US-born Blacks less than 25 years of age, we find no meaningful association between WIC and fetal growth among twins despite their elevated risk of anemia and adverse birth outcomes. We conclude that participation in WIC has had a minimal impact on infant health in the City over the past 14 years.

We speculate that the association found between 1988 and 1990, especially for US-born Blacks, resulted from unobserved heterogeneity related to differential rates of exposure to crack cocaine between WIC and non-WIC participants. As evidence, we show that exposure to cocaine and heroin was much greater among US-born Blacks than foreign-born Hispanics as recorded on New York City birth certificates. Although the birth certificate likely underreports exposure, relative differences by race and ethnicity are consistent with more rigorous studies of prenatal cocaine use. Moreover, differences in low birth weight by WIC among blacks diminished overtime as did reports of exposure to cocaine and heroin. Second, there are no birth weight differences by WIC between 1988 and 1991 among foreign-born Hispanics, a result consistent with their minimum exposure. Third, the convergence in rates of low birth weight 
between WIC and non-WIC participants results from a substantial decline among non-WIC participants, which is again consistent with the declining prenatal exposure to cocaine.

We anticipate that many will question the generalizability of our results, since they pertain to one city, albeit the most populous in the nation and one with an exceedingly large caseload of WIC participants. However, our results are quite consistent with the literature with respect to the generally weak association between WIC and fetal growth. This includes the recent study by Bitler and Currie (forthcoming) based on PRAMS in 19 states, as well as Gordon and Nelson's (1995) national analysis of WIC using the NMIHS. We emphasize the results for fetal growth because the link between nutritional supplementation and preterm birth in a developed country such as the US appears implausible given the lack of any effective interventions for preterm birth. Indeed, the seminal work on the Dutch famine is instructive. Despite dramatic nutritional deprivation relative to that which exists in the US today, there was no increase in preterm birth, but a large decrease in birth weight adjusted for gestation.

Our analysis was unique in that we had sufficient observations to stratify analyses by race, ethnicity, nativity, parity as well as the timing of prenatal care initiation. We believe this goes a long way towards lessening unobserved heterogeneity, which may explain differences between our results and those of others. However, by limiting the analysis to women with no previous live births and who initiate prenatal care early, we may have eliminated participants who were at greater nutritional risk and who might have benefited from WIC. Our response was to undertake a separate analysis of twins, since multifetal pregnancies are at greater nutritional risk than single gestations and yet twinning is more plausibly exogenous than are other risk factors such as late prenatal care, smoking and teen pregnancy. We believe that the analysis of twins is a meaningful contribution to the literature on WIC. 
Finally, we want to emphasize that women and infants represent roughly half of all WIC participants and that birth outcomes are only one outcome of interest. The fact that many women participate in WIC over multiple pregnancies implies a continuity that may have important pediatric benefits. Moreover, the lack of an association between prenatal WIC participation and adverse birth outcomes should be seen as a challenge to find more effective interventions such as smoking cessation programs, than as a reason to withdraw from the struggle to understand and ameliorate the high rate of low birth weight among poor and nearpoor women in the US. 


\section{Acknowledgements}

This research was supported by a grant from the Institute for Research on Poverty and the United States Department of Agriculture (IRP-USDA) Small Grants program to the Research Foundation of the City University of New York. We are grateful to Janet Currie and Marianne Bitler for comments and to John Karl Scholz and other participants at the USDA-IRP Small Grants workshop. We thank the New York City Department of Health and Mental Hygiene (NYCDOHMH) for the public use birth files. The opinions expressed are those of the authors and not the IRP, the USDA or the NYCDOHMH. 


\section{References:}

Ahluwalia, I. B., Hogan, V. K., Grummer-Strawn, L., Colville, W. R. and A. Peterson. (1998) "The Effect of WIC Participation on Small-for-Gestational-Age Births: Michigan, 1992." American Journal of Public Health 88(9): 1374-1377.

Alexander, G. et al. (1998). "What are the Fetal Growth Patterns of Singleton, Twins and Triplets in the United States." Clinical Obstetrics and Gynecology 41 (1): 115-125.

Alexander, G. and K. Korenbrot (1995). "The Role of Prenatal Care in Preventing Low Birth Weight." The Future of Children 5, 103-120.

American College of Obstetricians and Gynecologists. (1999). "Special Problems of Multiple Gestations.” International Journal of Gynecology and Obstetrics 64:323-333.

Angrist, J., Imbens, G., and D. Rubin. (1996) "Identification of Causal Effects Using Instrumental Variables. Journal of the American Statistical Association 91:444-454.

Avruch, S. and A. P. Cackley. (1995). "Savings Achieved by Giving WIC Benefits to Women Prenatally." Public Health Reports 110(1): 27-34.

Becker, Sascha O. and A. Ichino. (2002) "Estimation of Average Treatment Effects based on Propensity Scores.” Stata Journal 2(4):358-377.

Besharov, D. J. and P. Germanis, P. (2000). "Evaluating WIC.” Evaluation Review 24(2):123190.

Besharov, D. J. and P. Germanis. (2001). Rethinking WIC. An Evaluation of the Women, Infants, and Children Program. Washington, DC:American Enterprise Institute.

Bitler, Marianne and Janet Currie. Forthcoming. "Does WIC Work? The Effects of WIC on Pregnancy and Birth Outcomes." Journal of Policy Analysis and Management

Bitler, Marianne, Currie, Janet and John Karl Scholz. (2003). "WIC Eligibility and Participation." The Journal of Human Resources 38(Supplement): 1139-1179.

Brien, M. J. and C. A. Swann. (1999). "Prenatal Participation and Infant Health: Selection and Maternal Fixed Effects." Unpublished Manuscript, University of Virginia.

Bound, J., Jaeger, D. and R. Baker. (1995) "The Cure Can Be Worse than the Disease: A Cautionary Tale Regarding Instrumental Variables." Journal of the American Statistical Association 90:443-450.

Buescher, P. et al. (1993). "Prenatal WIC Participation Can Reduce Low Birth Weight and Newborn Medical Costs: a Cost-Benefit Analysis of WIC Participation in North Carolina." Journal of the American Dietetic Association 93(2):163-167. 
Buescher, Paul A. and Stephanie J. Horton. (2000). "Prenatal WIC Participation in Relation to Low Birth Weight and Medicaid Infant Costs in North Carolina - a 1997 Update.” Center for Health Information and Statistics, North Carolina Department of Health and Human Services.

Collaborative Group on Preterm Birth Prevention. (1993). "Multicenter Randomized, Controlled Trial of a Preterm Birth Prevention Program." American Journal of Obstetrics and Gynecology, 169: 352-366.

Devaney, B., Bilheimer, L. and J. Schore. (1992). "Medicaid Costs and Birth Outcomes: The Effects of Prenatal WIC Participation and the Use of Prenatal Care." Journal of Policy Analysis and Management 11(4): 573-592.

Dyson, D. et al. (1998). "Monitoring Women at Risk for Preterm Labor." New England Journal of Medicine 338(1):15-19.

Fraker, T., Gordon, A. and B. Devaney. (1995). "The Use of Selection-Bias Models to Evaluate Food and Nutrition Programs.” Washington, D.C.: Mathematica Policy Research, Inc.

Gall, S. A. 1996. Multiple Pregnancy and Delivery. St Louis, MO: Mosby.

General Accounting Office 1992. "Early Intervention: Federal Investments Like WIC Can Produce Savings" (GAO/HRD-92-18). Washington DC: United States General Accounting Office.

Goldenberg, R. L. and Rouse, D. J. (1998). "Prevention of Premature Birth." The New England Journal of Medicine 339(5): 313-320.

Gordon, Anne and Lyle Nelson. (1995) "Characteristics and Outcomes of WIC Participants and Nonparticipants: Analysis of the 1988 National Maternal and Infant Health Survey." Princeton: Mathematica Policy Institute.

Heckman, J. (1997). "Instrumental Variables.” Journal of Human Resources 32(3):441-462.

Iams, J. (1998). "Prevention of Preterm Birth.” New England Journal of Medicine 338(1):54-56.

Institute of Medicine. (1990). Nutrition During Pregnancy. Washington, D.C.: National Academy Press.

Institute of Medicine. (1996). WIC Nutrition and Risk Criteria. Washington, D.C.: National Academy Press.

Jain, T., Missmer, S.A. and M.D. Hornstein. (2004). "Trends in Embryo-Transfer Practice and in Outcomes of the Use of Assisted Reproductive Technology in the United States." The New England Journal of Medicine 350(16):1639-1645.

Joyce, T. (1999) "Impact of Augmented Prenatal Care on Birth Outcomes of Medicaid Recipients in New York City." Journal of Health Economics 18(1): 31-67. 
Joyce, et al. (1995). "The Impact of Prenatal Exposure to Cocaine on Newborn Costs and Length of Stay.” Health Services Research 30:341-358.

Kennedy, E.T. et al. (1982). "Evaluation of the Effect of WIC Supplemental Feeding on Birth Weight" Journal of the American Dietetic Association. 80:220-227.

Kennedy, E.T. and M. Kotelchuck. (1984). "The Effect of WIC-Supplemented Feeding on Birth Weight: A Case-control Analysis" The American Journal of Clinical Nutrition 40:579585.

Kotelchuck, M. (1994). “An Evaluation of the Kessner Adequacy of Prenatal Care Index and a Proposed Adequacy of Prenatal Care Utilization Index." American Journal of Public Health 84(10), 1414-1420.

Kotelchuck, M. et al. (1984). "WIC Participation and Pregnancy Outcomes: Massachusetts Statewide Evaluation Project.” American Journal of Public Health 74(10):1086-1092.

Kowaleski-Jones, L. and G. J. Duncan. (2002) "Effects of Participation in the WIC Program on Birthweight: Evidence from the National Longitudinal Survey of Youth." American Journal of Public Health 92(5): 799-804.

Lewis, K. and M. Ellwood. (2000). "Medicaid Policies and Eligibility for WIC.” Cambridge, MA: Mathematica Policy Research, Inc.

McCalla, S. et al. (1991). "The Biologic and Social Consequences of Perinatal Cocaine Use in an Inner-City Population: Results of An Anonymous Cross-Sectional Study." American Journal of Obstetrics \& Gynecology 164, 625-30.

Metcoff, J. et al. (1985). "Effect of Food Supplementation (WIC) During Pregnancy on Birth Weight." American Journal of Clinical Nutrition 41:933-947.

Moss, N. E. and Carver, K. (1998) "The Effect of WIC and Medicaid on Infant Mortality in the United States." American Journal of Public Health 88(9): 1354-1361.

New York State Department of Health, Bureau of Nutrition (1990). "The New York State WIC Evaluation: The Association Between Prenatal WIC Participation and Birth Outcomes."

Phibbs, C. et al. (1991). “The Neonatal Costs of Maternal Cocaine Use.” Journal of the American Medical Association 266(11): 1521-1526.

Rush, David et al. (1988) "Longitudinal Study of Pregnant Women." American Journal of Clinical Nutrition 48: P. 439-438.

Rush, David, Stein, Zena and Mervyn Susser. (1980). Diet in Pregnancy: A Randomized Controlled Trial of Nutritional Supplements. New York: Alan R. Liss, Inc. 
Schieve, L. A. et al. (2002). "Low and Very Low Birth Weight in Infants Conceived with Use of Assisted Reproductive Technology.” New England Journal of Medicine 346(10):731737.

Schramm, W. F. (1985). "WIC Prenatal Participation and Its Relationship to Newborn Medicaid Costs in Missouri: A Cost/Benefit Analysis." American Journal of Public Health 75(8): 851-857.

Schramm, W. F. (1986). "Prenatal Participation in WIC Related to Medicaid Costs for Missouri Newborns: 1982 Update." Public Health Reports 101(6): 607-615.

Stein, Zena and Mervyn Susser. (1975). "The Dutch Famine, 1944-1945, and the Reproductive Process. I. Effects on the Six Indices at Birth.” Pediatric Research 9:70-76.

Stockbauer, J. (1986). "Evaluation of the Missouri WIC Program: Prenatal Components." Journal of the American Dietetic Association 86: 61-67.

Stockbauer, J. W. (1987). "WIC Prenatal Participation and Its Relation to Pregnancy Outcomes in Missouri: A Second Look." American Journal of Public Health 77(7): 813-818.

U.S. House of Representatives: Committee on Ways and Means. (2000). 2000 Green Book Washington D.C.: U.S. Government Printing Office.

Vega, W. A. et al. (1997). "Perinatal Drug Use among Immigrant and Native-Born Latinas." Substance Use \& Misuse 32: 43-62.

Vega, W. A. et al. (1993). "Prevalence and Magnitude of Perinatal Substance Exposures in California." New England Journal of Medicine 329: 850-4.

Ventura, S. J. and S. M. Taffel. (1985). Childbearing Characteristics of U.S.- and Foreign-born Hispanic Mothers. Public Health Reports 100: 647-652.

Ventura, S.J., et al. (1999). "Births: Final Data for 1997." National Vital Statistics Report 47(18). http://www.cdc.gov/nchs/data/nvsr/nvsr49/nvsr49_01.pdf

Weeks, J. R., Rumbaut, R. G., (1991). Infant Mortality Among Ethnic Immigrant Groups. 327334. Social Science \& Medicine 33:327-34.

Wooldridge, J. M. (2002). Econometric Analysis of Cross Section and Panel Data. Cambridge, MA: M.I.T. Press. 
Figure 1. Percent of Singleton Births with Weight less than 2500g to

Women on Medicaid or WIC, by Participation in WIC, NYC 1988-2001

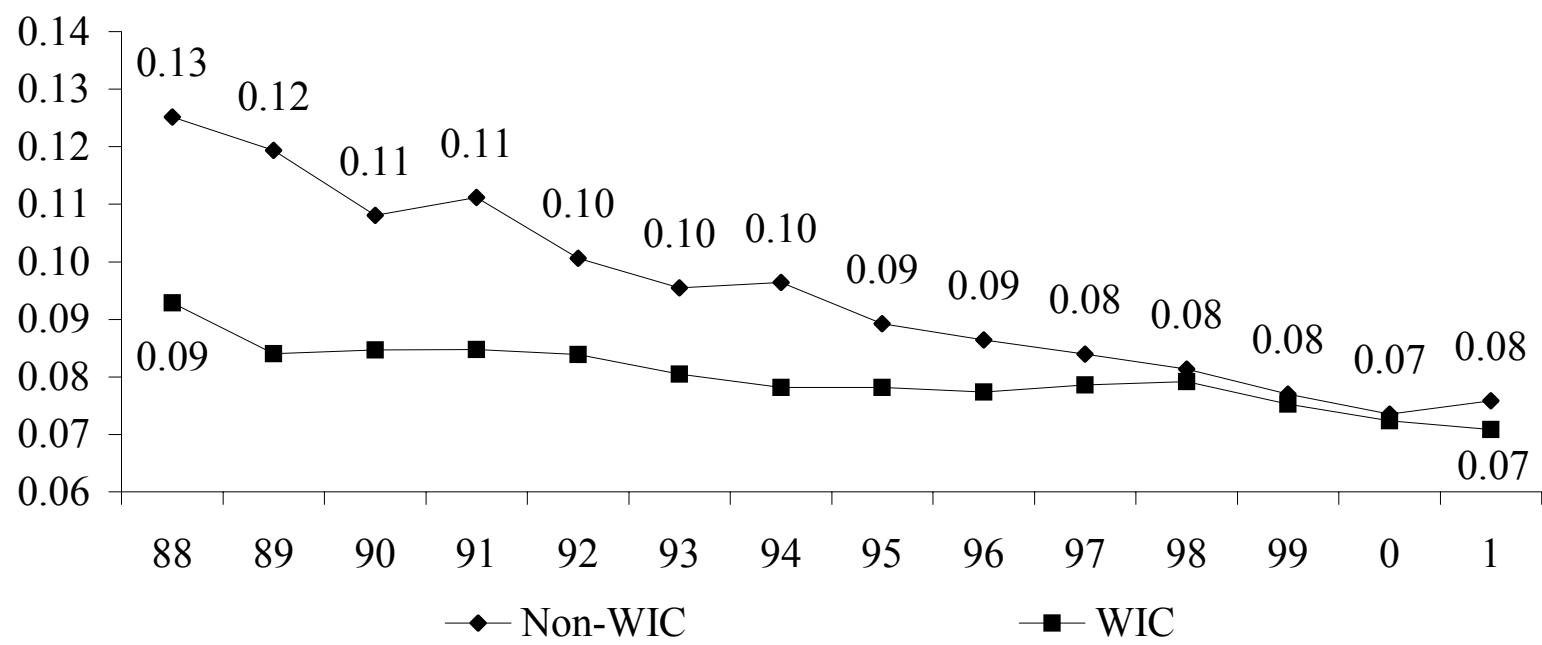

Figure 2. Mean Birth Weight (in grams) for Singleton Births to Women on Medicaid or WIC, by Participation in WIC, NYC 1988-2001

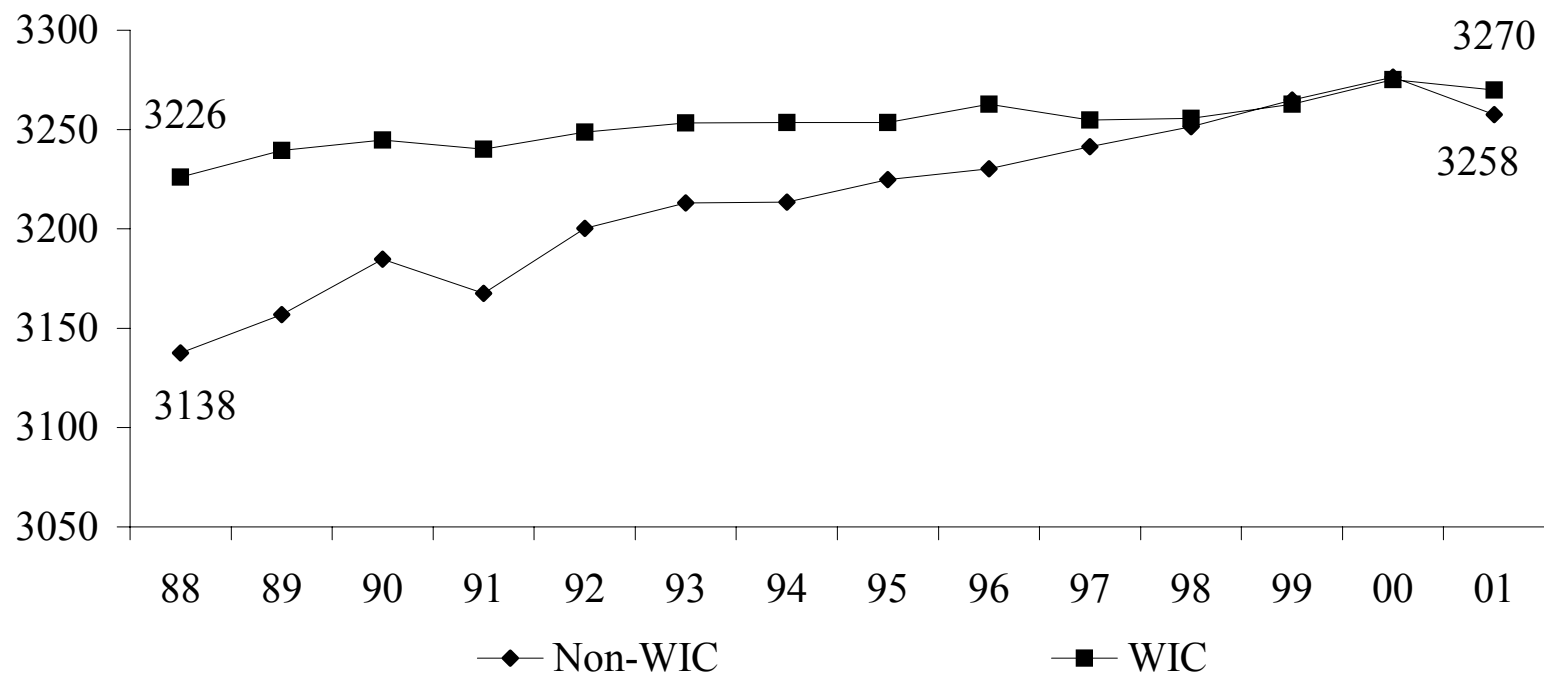


Figure 3. Percent of Singleton Births Exposed to Cocaine or Heroin among Women on Medicaid and/or WIC who Initiated Prenatal Care in the First Four Months of Pregnancy, by Nativity and Participation in

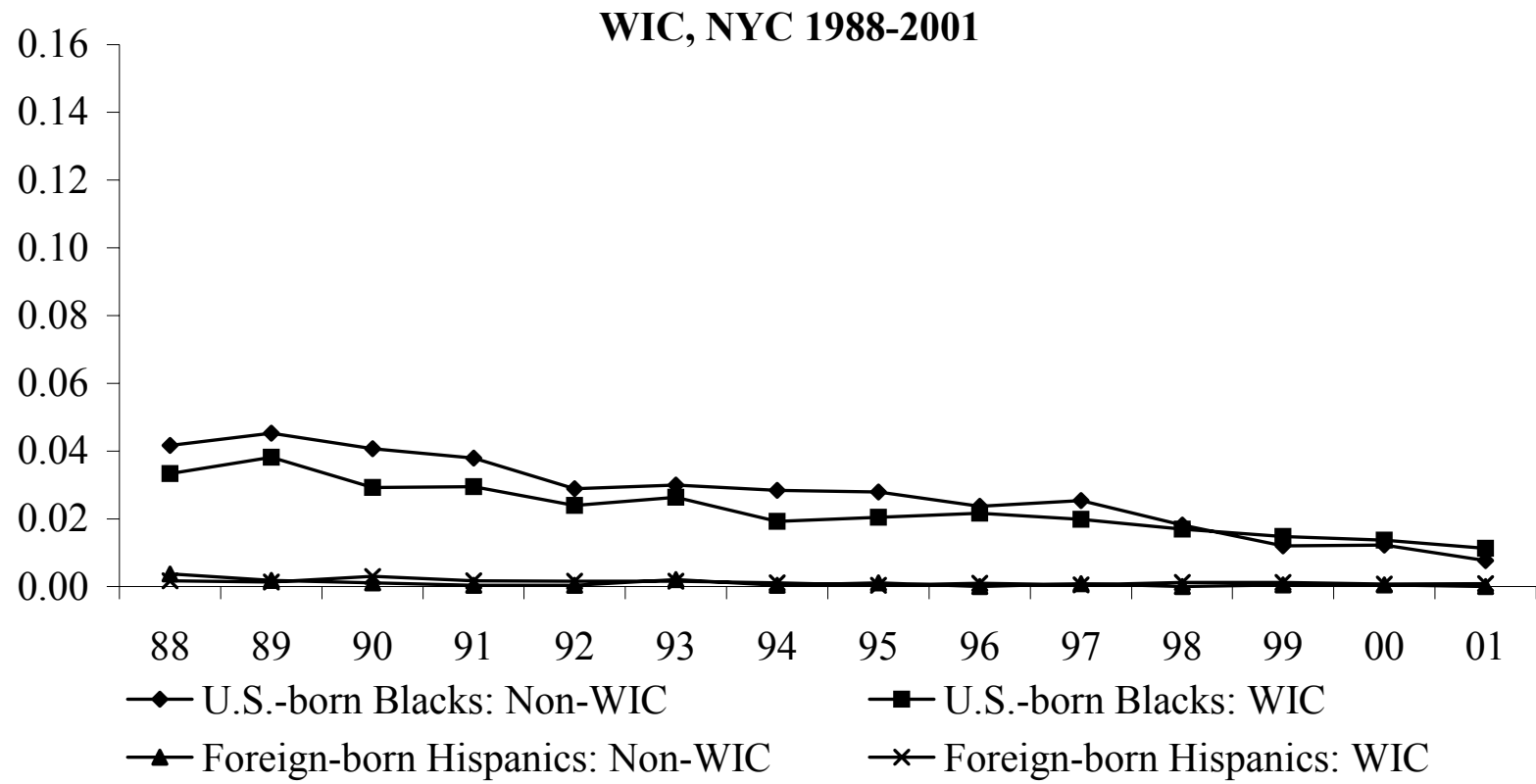

Figure 4. Percent of Singleton Births Exposed to Cocaine or Heroin among Women on Medicaid and/or WIC who did not Initiate Prenatal Care in the First Four Months of Pregnancy, by Nativity and

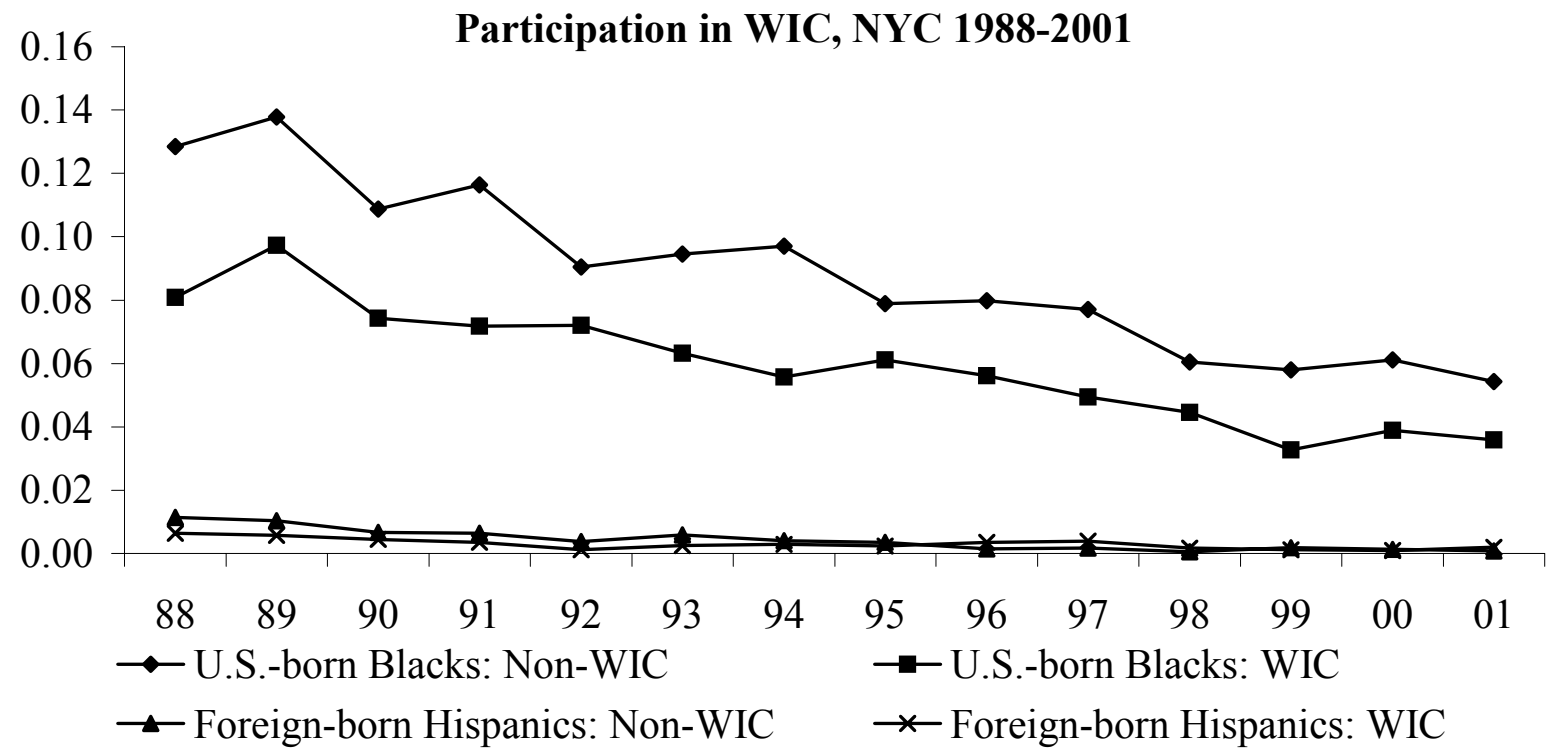


Table 1. Percent of Births to Women on WIC in New York City, by Source and Year

\begin{tabular}{|c|c|c|c|c|}
\hline & NMIHS $^{\text {a }}$ & $\begin{array}{c}\text { NY Department of } \\
\text { Health }^{b}\end{array}$ & $\begin{array}{l}\text { NYC Birth } \\
\text { Certificates }\end{array}$ & PRAMS $^{c}$ \\
\hline 1988 & $\begin{array}{c}28.0 \% \\
(\mathrm{~N}=1,735)\end{array}$ & $\begin{array}{c}21.3 \% \\
(\mathrm{~N}=71,628)^{*}\end{array}$ & $\begin{array}{c}21.0 \% \\
(\mathrm{~N}=74,294)^{*}\end{array}$ & \\
\hline 1993 & & & $\begin{array}{c}34.8 \% \\
(\mathrm{~N}=124,010)\end{array}$ & $\begin{array}{c}33.7 \% \\
(\mathrm{~N}=1,087)\end{array}$ \\
\hline $\begin{array}{l}\text { a } 1988 \mathrm{I} \\
\mathrm{b} \text { "The I } \\
\text { Outcom } \\
{ }^{\mathrm{c}} \text { Percen } \\
\text { System; } \\
\text { WIC ev } \\
\text { number } \\
{ }^{*} \text { Based }\end{array}$ & $\begin{array}{l}\text { Maternal and Inf } \\
\text { State WIC Eva } \\
\text { York State Dep } \\
\text { s on WIC in Ne } \\
\text { of WIC particip } \\
\text { number of live } \\
\text { irths in NYC wa } \\
\text { le of births from }\end{array}$ & $\begin{array}{l}\text { Health Survey, live birth sa } \\
\text { ion: The Association Betw } \\
\text { ent of Health, Bureau of N } \\
\text { ork State was estimated us } \\
\text { that reside in New York C } \\
\text { ss in NY was obtained from } \\
\text { tained from the Summary } \\
\text { te to December of } 1988 \text {. }\end{array}$ & $\begin{array}{l}\text { ple, North East Re } \\
\text { n Prenatal WIC Pa } \\
\text { rition, December } 1 \\
\text { the Pregnancy Ri } \\
\text { was obtained fron } \\
\text { ne Statistical Abstr } \\
\text { Vital Statistics, N }\end{array}$ & $\begin{array}{l}\text { on and Birth } \\
8-20 . \\
\text { sment Monitoring } \\
38 \text { New York State } \\
\text { e United States; }\end{array}$ \\
\hline
\end{tabular}


Table 2. Characteristics of Singleton Births on WIC and/or Medicaid for Women with No Previous Live Births, who Initiated Prenatal Care in the First Four Months of Pregnancy, New York City 1988-2001

\begin{tabular}{|c|c|c|c|c|c|c|c|c|c|}
\hline & \multicolumn{3}{|c|}{ 1988-1990 } & \multicolumn{3}{|c|}{ 1994-1996 } & \multicolumn{3}{|c|}{ 1999-2001 } \\
\hline & Non-WIC & WIC & Diff. & Non-WIC & WIC & Diff. & Non-WIC & WIC & Diff. \\
\hline $\mathrm{N}$ & 16745 & 18670 & & 14630 & 36029 & & 13561 & 39047 & \\
\hline \multicolumn{10}{|l|}{ Measure of birth weight: } \\
\hline Mean & 3188 & 3216 & $28.53 * * *$ & 3219 & 3215 & -3.858 & 3238 & 3216 & $-21.688 * * *$ \\
\hline$\%$ LBW $\quad(<2500 \mathrm{~g})$ & 0.098 & 0.085 & $-0.013 * * *$ & 0.082 & 0.080 & -0.003 & 0.073 & 0.080 & $0.007 * *$ \\
\hline$\%$ VLBW $(<1500 \mathrm{~g})$ & 0.017 & 0.013 & $-0.004 * * *$ & 0.015 & 0.015 & 0.000 & 0.014 & 0.014 & 0.000 \\
\hline \multicolumn{10}{|l|}{ Weeks of gestation: } \\
\hline Mean & 38.90 & 39.07 & $0.176^{* * *}$ & 38.93 & 38.97 & $0.040^{*}$ & 38.89 & 38.91 & 0.018 \\
\hline \% Unknown & 0.000 & 0.000 & 0.000 & 0.000 & 0.000 & 0.000 & 0.002 & 0.000 & $-0.002 * * *$ \\
\hline Premature & 0.101 & 0.083 & $-0.018 * * *$ & 0.088 & 0.081 & $-0.006^{* *}$ & 0.078 & 0.081 & 0.003 \\
\hline \multicolumn{10}{|l|}{ Measure of fetal growth: } \\
\hline LBW, $>36$ wks gest & 0.042 & 0.039 & $-0.004 *$ & 0.032 & 0.033 & 0.001 & 0.029 & 0.032 & 0.002 \\
\hline Small-for-GA & 0.167 & 0.159 & $-0.007 *$ & 0.143 & 0.144 & 0.001 & 0.123 & 0.139 & $0.016 * * *$ \\
\hline \% Unknown & 0.001 & 0.001 & $-0.001 *$ & 0.001 & 0.001 & 0.000 & 0.003 & 0.001 & $-0.003 * * *$ \\
\hline \multicolumn{10}{|l|}{ Mother's weight-gain: } \\
\hline Mean & 29.24 & 30.62 & $1.382 * * *$ & 31.32 & 31.91 & $0.582 * * *$ & 32.64 & 32.93 & $0.284 * *$ \\
\hline \% Unknown & 0.676 & 0.265 & $-0.412 * * *$ & 0.279 & 0.182 & $-0.097 * * *$ & 0.086 & 0.059 & $-0.027 * * *$ \\
\hline Net weight & 22.19 & 23.51 & $1.324 * * *$ & 24.20 & 24.81 & $0.611 * * *$ & 25.51 & 25.83 & $0.328 * *$ \\
\hline \multicolumn{10}{|l|}{ Mother's education: } \\
\hline$<12$ years & 0.397 & 0.397 & 0.000 & 0.310 & 0.363 & $0.053 * * *$ & 0.308 & 0.375 & $0.067 * * *$ \\
\hline 12 years & 0.447 & 0.404 & $-0.043 * * *$ & 0.424 & 0.390 & $-0.034 * * *$ & 0.388 & 0.371 & $-0.018 * * *$ \\
\hline $13-16$ years & 0.126 & 0.171 & $0.045^{* * *}$ & 0.209 & 0.200 & $-0.008 * *$ & 0.241 & 0.217 & $-0.024 * * *$ \\
\hline$\geq 17$ years & 0.010 & 0.012 & 0.002 & 0.026 & 0.020 & $-0.006^{* * *}$ & 0.040 & 0.027 & $-0.014 * * *$ \\
\hline Unknown & 0.019 & 0.016 & $-0.003 * *$ & 0.031 & 0.027 & $-0.004 * * *$ & 0.022 & 0.011 & $-0.011 * * *$ \\
\hline \multicolumn{10}{|l|}{ Mother's age: } \\
\hline $10-19$ & 0.260 & 0.299 & $0.039 * * *$ & 0.234 & 0.295 & $0.061 * * *$ & 0.201 & 0.276 & $0.076 * * *$ \\
\hline $20-34$ & 0.687 & 0.665 & $-0.022 * * *$ & 0.712 & 0.666 & $-0.046 * * *$ & 0.742 & 0.684 & $-0.058 * * *$ \\
\hline $35-50$ & 0.050 & 0.034 & $-0.017 * * *$ & 0.054 & 0.038 & $-0.016^{* * *}$ & 0.058 & 0.040 & $-0.017 * * *$ \\
\hline Unknown & 0.003 & 0.002 & 0.000 & 0.001 & 0.001 & -0.000 & 0.000 & 0.000 & 0.000 \\
\hline
\end{tabular}


Table 2. Continued

\begin{tabular}{|c|c|c|c|c|c|c|c|c|c|}
\hline & \multicolumn{3}{|c|}{ 1988-1990 } & \multicolumn{3}{|c|}{ 1994-1996 } & \multicolumn{3}{|c|}{ 1999-2001 } \\
\hline & Non-WIC & WIC & Diff. & Non-WIC & WIC & Diff. & Non-WIC & WIC & Diff. \\
\hline \multicolumn{10}{|l|}{ Mother's race: } \\
\hline Puerto Rican & 0.197 & 0.224 & $0.027 * * *$ & 0.124 & 0.153 & $0.030 * * *$ & 0.103 & 0.117 & $0.015 * * *$ \\
\hline Other-Hispanic & 0.234 & 0.263 & $0.029 * * *$ & 0.255 & 0.353 & $0.098 * * *$ & 0.251 & 0.378 & $0.128 * * *$ \\
\hline Asian & 0.036 & 0.019 & $-0.017 * * *$ & 0.177 & 0.049 & $-0.128 * * *$ & 0.258 & 0.087 & $-0.172 * * *$ \\
\hline White-NonHispanic & 0.117 & 0.066 & $-0.051 * * *$ & 0.174 & 0.082 & $-0.092 * * *$ & 0.158 & 0.071 & $-0.087 * * *$ \\
\hline Black-NonHispanic & 0.404 & 0.424 & $0.020 * * *$ & 0.257 & 0.351 & $0.093 * * *$ & 0.226 & 0.342 & $0.116^{* * *}$ \\
\hline Other & 0.000 & 0.000 & $-0.000 * *$ & 0.009 & 0.007 & $-0.002 * * *$ & 0.002 & 0.004 & $0.002 * * *$ \\
\hline Unknown & 0.013 & 0.003 & $-0.009 * * *$ & 0.004 & 0.005 & $0.001 *$ & 0.003 & 0.001 & $-0.002 * * *$ \\
\hline \multicolumn{10}{|l|}{ Marital status: } \\
\hline Single & 0.684 & 0.684 & 0.000 & 0.667 & 0.766 & $0.099 * * *$ & 0.617 & 0.745 & $0.128 * * *$ \\
\hline Unknown & 0.000 & 0.000 & 0.000 & 0.000 & 0.000 & 0.000 & 0.000 & 0.000 & 0.000 \\
\hline \multicolumn{10}{|l|}{ Mother's birth place: } \\
\hline Foreign born & 0.404 & 0.435 & $0.030 * * *$ & 0.579 & 0.545 & $-0.034 * * *$ & 0.628 & 0.585 & $-0.043 * * *$ \\
\hline \% Unknown & 0.003 & 0.003 & 0.001 & 0.008 & 0.008 & 0.000 & 0.009 & 0.004 & $-0.005 * * *$ \\
\hline \multicolumn{10}{|l|}{ PrePregnancy Weight: } \\
\hline Mean & 137.2 & 139.1 & $1.883 * * *$ & 134.6 & 140.8 & $6.189 * * *$ & 134.0 & 138.1 & $4.124 * * *$ \\
\hline \% Unknown & 0.662 & 0.235 & $-0.427 * * *$ & 0.256 & 0.157 & $-0.100 * * *$ & 0.078 & 0.048 & $-0.030 * * *$ \\
\hline \multicolumn{10}{|l|}{ Prenatal doctor visits: } \\
\hline Mean & 9.456 & 10.202 & $0.745^{* * *}$ & 10.331 & 10.414 & $0.083 * *$ & 10.361 & 10.666 & $0.305^{* * *}$ \\
\hline \% Unknown & 0.035 & 0.020 & $-0.015 * * *$ & 0.027 & 0.024 & $-0.003 *$ & 0.022 & 0.008 & $-0.014 * * *$ \\
\hline \multicolumn{10}{|l|}{ Drug use d. pregnancy: } \\
\hline Heroin/cocaine & 0.013 & 0.009 & $-0.004 * * *$ & 0.003 & 0.003 & -0.001 & 0.001 & 0.002 & 0.000 \\
\hline \% Unknown & 0.024 & 0.020 & $-0.004 * *$ & 0.021 & 0.018 & $-0.003 * *$ & 0.001 & 0.000 & $0.000 *$ \\
\hline Cigarettes & 0.049 & 0.057 & $0.008 * * *$ & 0.042 & 0.037 & $-0.005 * *$ & 0.019 & 0.027 & $0.008 * * *$ \\
\hline
\end{tabular}


Table 3. Differences in Birth Weight between WIC and Non-WIC Participants for Singleton Births in New York City 1988-2001 for Women on WIC and/or Medicaid by Timing of Prenatal Care and Parity

Adjusted Mean Difference

\begin{tabular}{|c|c|c|c|c|}
\hline & $\begin{array}{c}\text { Unadjusted Mean } \\
\text { Difference }\end{array}$ & All Women & $\begin{array}{c}\text { Early Prenatal } \\
\text { Care }\end{array}$ & $\begin{array}{c}\text { Early Care, } \\
\text { First Birth }\end{array}$ \\
\hline All years & $46.01 * *$ & $25.92 * *$ & $18.02 * *$ & $10.53 * *$ \\
\hline 1988 & $88.17 * *$ & $55.16 * *$ & $36.69 * *$ & $33.13 * *$ \\
\hline 1989 & $86.44 * *$ & $51.72 * *$ & $40.16 * *$ & $35.82 * *$ \\
\hline 1990 & $61.35 * *$ & $40.27 * *$ & $32.28 * *$ & $21.89 *$ \\
\hline 1991 & $76.62 * *$ & $51.01 * *$ & $39.09 * *$ & $24.02 *$ \\
\hline 1992 & $50.99 * *$ & $24.21 * *$ & 10.07 & 15.14 \\
\hline 1993 & $43.22 * *$ & $20.13 * *$ & 12.45 & -2.21 \\
\hline 1994 & $40.29 * *$ & $25.79 * *$ & $30.97 * *$ & $21.90 *$ \\
\hline 1995 & $24.73 * *$ & $22.12 * *$ & $14.06 *$ & 3.57 \\
\hline 1996 & $31.40 * *$ & $23.98 * *$ & $13.33 *$ & 2.80 \\
\hline 1997 & $10.99 *$ & $11.44 *$ & 1.53 & -0.99 \\
\hline 1998 & 2.74 & 10.15 & $21.63 * *$ & 17.56 \\
\hline 1999 & -3.88 & 5.48 & 6.47 & 2.33 \\
\hline 2000 & -2.19 & -2.15 & -2.17 & $-20.20 *$ \\
\hline 2001 & $11.73 *$ & $12.98 *$ & 5.43 & 0.70 \\
\hline $\mathrm{N}$ & & 870444 & 485921 & 211138 \\
\hline
\end{tabular}

All models include dummy variables for race/ethnicity (6), marital status (1), parity (2), mother's education (4), mother's age (3), heroin or cocaine use (2), smoking (1), health center districts (29) and years (13). The six birth outcomes are mean birth weight, a dichotomous indicator of birth weight less than 2500 grams (LBW) or less than 1500 grams (VLBW), mean birth weight adjusted for gestational age, a dichotomous indicator for infants that are small for gestational age (SGA), and a dichotomous indicator for low birth weight births born after 36 weeks gestation (Term LBW). All estimates are obtained by ordinary least squares with robust standard errors. 
Table 4. Differences in Birth Outcomes between WIC and Non-WIC Participants for Singleton Births in New York City 1988-2001 for Women on WIC and/or Medicaid, Who Have No Previous Live Births and Who Initiated Prenatal Care in the First Four Months of Pregnancy

\begin{tabular}{|c|c|c|c|c|c|c|}
\hline & \multicolumn{3}{|c|}{ Measure of Birth Weight } & \multicolumn{3}{|c|}{ Measure of Fetal Growth } \\
\hline & Mean & $<2500 \mathrm{~g}$ & $<1500 \mathrm{~g}$ & $\begin{array}{r}\text { Weight } \\
\text { Gestation }\end{array}$ & SGA & Term LBW \\
\hline All years & $10.532 * *$ & $-0.006 * *$ & $-0.003 * *$ & $-5.888 * *$ & 0.003 & 0.000 \\
\hline 1988 & $33.127 * *$ & -0.008 & -0.004 & 1.899 & -0.008 & 0.000 \\
\hline 1989 & $35.821 * *$ & $-0.018 * *$ & -0.004 & 4.213 & -0.004 & -0.006 \\
\hline 1990 & $21.886 *$ & $-0.011 *$ & -0.003 & -5.327 & 0.003 & -0.001 \\
\hline 1991 & $24.019 *$ & -0.008 & -0.002 & 13.706 & -0.003 & $-0.010 * *$ \\
\hline 1992 & 15.138 & -0.006 & 0.000 & 15.509 & -0.007 & 0.000 \\
\hline 1993 & -2.206 & 0.004 & -0.002 & -3.503 & 0.002 & $0.008 *$ \\
\hline 1994 & $21.899 *$ & $-0.022 * *$ & $-0.006 * *$ & -0.613 & -0.005 & -0.005 \\
\hline 1995 & 3.566 & -0.005 & -0.001 & -9.256 & -0.007 & -0.003 \\
\hline 1996 & 2.799 & 0.000 & -0.002 & -14.506 & $0.013 *$ & $0.007 *$ \\
\hline 1997 & -0.990 & 0.002 & 0.000 & -15.015 & 0.006 & 0.005 \\
\hline 1998 & 17.555 & -0.009 & $-0.006 * *$ & -4.116 & 0.011 & -0.002 \\
\hline 1999 & 2.332 & -0.007 & -0.003 & $-25.782 * *$ & $0.021 * *$ & -0.002 \\
\hline 2000 & $-20.204 *$ & 0.002 & -0.004 & $-34.064 * *$ & 0.010 & 0.003 \\
\hline 2001 & 0.702 & 0.002 & -0.002 & -2.693 & 0.005 & 0.001 \\
\hline $\mathrm{N}$ & 211138 & 211138 & 211138 & 211093 & 210375 & 211093 \\
\hline
\end{tabular}

All models include dummy variables for race/ethnicity (6), nativity (2), marital status (1), parity (2), mother's education (4), mother's age (3), heroin or cocaine use (2) and smoking (1), health center district (29) and years (13). The six birth outcomes are mean birth weight, a dichotomous indicator of birth weight less than 2500 grams (LBW) or less than 1500 grams (VLBW), mean birth weight adjusted for gestational age, a dichotomous indicator for infants that are small for gestational age (SGA), and a dichotomous indicator for low birth weight births born after 36 weeks gestation (Term LBW). All estimates are obtained by ordinary least squares with robust standard errors. 
Table 5. Differences in Birth Outcomes between WIC and Non-WIC Participants for Singleton Births in New York City 1988-2001 for U.S.-born Non-Hispanic Blacks on WIC and/or Medicaid, Who Have No Previous Live Births and Who Initiated Prenatal Care in the First Four Months of Pregnancy

\begin{tabular}{|c|c|c|c|c|c|c|}
\hline & \multicolumn{3}{|c|}{ Measure of Birth Weight } & \multicolumn{3}{|c|}{ Measure of Fetal Growth } \\
\hline & Mean & $<2500 \mathrm{~g}$ & $<1500 \mathrm{~g}$ & $\begin{array}{r}\text { Weight | } \\
\text { Gestation }\end{array}$ & SGA & Term LBW \\
\hline All years & $41.295 * *$ & $-0.020 * *$ & $-0.007 * *$ & 4.772 & 0.000 & -0.003 \\
\hline 1988 & $61.457 * *$ & -0.021 & -0.003 & 20.546 & -0.004 & -0.007 \\
\hline 1989 & $59.205 * *$ & $-0.037 * *$ & -0.010 & -9.110 & 0.017 & -0.003 \\
\hline 1990 & 36.759 & $-0.026 *$ & -0.009 & $-38.505 *$ & 0.017 & 0.004 \\
\hline 1991 & $73.049 * *$ & $-0.025 *$ & $-0.013 *$ & $38.113 *$ & $-0.031 *$ & $-0.016 *$ \\
\hline 1992 & $51.467 *$ & -0.019 & 0.004 & $44.961 *$ & -0.008 & -0.005 \\
\hline 1993 & 25.168 & 0.004 & -0.010 & 20.087 & -0.012 & 0.003 \\
\hline 1994 & $69.624 * *$ & $-0.047 * *$ & $-0.012 *$ & 27.334 & -0.006 & -0.015 \\
\hline 1995 & 19.761 & -0.002 & 0.003 & 8.045 & -0.003 & 0.001 \\
\hline 1996 & 29.623 & $-0.027 *$ & -0.007 & -9.629 & 0.018 & -0.004 \\
\hline 1997 & 3.506 & -0.010 & 0.003 & -16.252 & 0.014 & 0.010 \\
\hline 1998 & 40.184 & -0.015 & $-0.017 *$ & -4.966 & 0.005 & -0.008 \\
\hline 1999 & 62.013 & -0.016 & -0.014 & -21.624 & 0.010 & 0.010 \\
\hline 2000 & -16.877 & 0.002 & -0.005 & -24.199 & -0.002 & 0.002 \\
\hline 2001 & 41.592 & $-0.026 *$ & $-0.018 * *$ & 16.285 & -0.008 & -0.009 \\
\hline $\mathrm{N}$ & 43463 & 43463 & 43463 & 43460 & 43460 & 43460 \\
\hline
\end{tabular}

See note for Table 4. 
Table 6. Differences in Birth Outcomes between WIC and Non-WIC Participants for Singleton Births in New York City 1988-2001 for Foreign-born Hispanic Women on WIC and/or Medicaid, Who Have No Previous Live Births and Who Initiated Prenatal Care in the First Four Months of Pregnancy

\begin{tabular}{|c|c|c|c|c|c|c|}
\hline & \multicolumn{3}{|c|}{ Measure of Birth Weight } & \multicolumn{3}{|c|}{ Measure of Fetal Growth } \\
\hline & Mean & $<2500 \mathrm{~g}$ & $<1500 \mathrm{~g}$ & $\begin{array}{r}\text { Weight | } \\
\text { Gestation }\end{array}$ & SGA & Term LBW \\
\hline All years & 8.274 & -0.004 & 0.001 & -1.733 & -0.004 & 0.000 \\
\hline 1988 & 28.136 & 0.001 & -0.003 & -11.659 & -0.014 & 0.012 \\
\hline 1989 & 19.270 & 0.000 & -0.007 & 2.556 & 0.010 & 0.008 \\
\hline 1990 & -2.612 & 0.003 & 0.002 & 9.506 & -0.008 & 0.002 \\
\hline 1991 & 15.945 & -0.006 & 0.003 & 10.461 & -0.005 & $-0.012 *$ \\
\hline 1992 & -6.333 & -0.006 & 0.004 & -3.333 & -0.004 & 0.000 \\
\hline 1993 & -1.095 & 0.008 & -0.001 & -4.193 & -0.006 & 0.007 \\
\hline 1994 & -0.785 & -0.017 & 0.000 & -10.853 & -0.009 & -0.006 \\
\hline 1995 & -11.652 & -0.007 & 0.004 & -10.198 & -0.015 & -0.007 \\
\hline 1996 & 30.101 & -0.007 & 0.001 & 4.405 & -0.018 & 0.005 \\
\hline 1997 & 16.021 & -0.009 & 0.000 & 0.593 & -0.004 & 0.003 \\
\hline 1998 & -2.178 & -0.012 & 0.002 & -4.989 & 0.013 & -0.008 \\
\hline 1999 & 33.378 & -0.017 & -0.001 & 14.761 & 0.004 & -0.005 \\
\hline 2000 & -28.462 & 0.011 & 0.006 & $-36.773 *$ & 0.010 & 0.006 \\
\hline 2001 & 32.745 & 0.000 & -0.001 & 15.328 & -0.008 & -0.004 \\
\hline $\mathrm{N}$ & 55896 & 55896 & 55896 & 55888 & 55888 & 55888 \\
\hline
\end{tabular}

See note for Table 4. 
Table 7. Differences in Birth Outcomes between WIC and Non-WIC Participants for Twin Deliveries in New York City 1988-2001 for Women on WIC and/or Medicaid who Initiated Prenatal Care in the First Four Months of Pregnancy

\begin{tabular}{ll}
\multicolumn{2}{c}{ Measure of Birth Weight } \\
\hline Mean $\quad<2500 \mathrm{~g}$ & $<1500 \mathrm{~g}$ \\
\hline
\end{tabular}

\begin{tabular}{cc} 
Measure of Fetal Growth \\
\hline $\begin{array}{c}\text { Weight } \\
\text { gestation }\end{array}$ & SGA $\quad$ Term LBW \\
\hline
\end{tabular}

Panel A: All Women $(\mathrm{N}=11,091)$

$\begin{array}{llllllr}\text { All years } & 28.646 * & -0.021 & -0.013 & 13.520 & -0.020 * * & -0.001 \\ 1988-1992 & 91.586 * * & -0.037 * & -0.052 * * & 28.228 & -0.028 * & 0.001 \\ 1993-1997 & 11.087 & -0.020 & 0.006 & 16.303 & -0.028 * & -0.006 \\ 1998-2001 & -21.347 & -0.003 & 0.009 & -5.761 & -0.001 & 0.000\end{array}$

Panel B: U.S.-Born Blacks $(\mathrm{N}=\mathbf{2 , 9 6 4 )}$

$\begin{array}{lllllll}\text { All years } & 25.298 & -0.030 & -0.008 & 55.505 * * & -0.039 * * & -0.027 \\ 1988-1992 & 104.102 * & -0.040 & -0.060 * * & 38.563 & -0.022 & -0.015 \\ 1993-1997 & -14.755 & -0.047 & 0.047 & 91.457 * * & -0.067 * * & -0.087 * * \\ 1998-2001 & -51.522 & 0.005 & 0.007 & 38.985 & -0.032 & 0.026\end{array}$

Panel C: Foreign-Born Hispanics $(\mathrm{N}=\mathbf{2 , 4 9 1 )}$

\begin{tabular}{|c|c|c|c|c|c|c|}
\hline All years & 22.137 & 0.005 & $-0.030 *$ & 8.427 & -0.006 & -0.026 \\
\hline 1988-1992 & 46.994 & -0.004 & $-0.048 *$ & 2.254 & 0.025 & -0.008 \\
\hline 1993-1997 & -59.296 & $0.083 *$ & -0.008 & -39.784 & -0.020 & 0.016 \\
\hline $1998-2001$ & 75.947 & -0.061 & -0.032 & 61.566 & -0.023 & $-0.084 * *$ \\
\hline
\end{tabular}

Panel A includes dummy variables for race/ethnicity (6), nativity (2), marital status (1), mother's education (4), mother's age (3), heroin or cocaine use (2) and smoking (1), health center district (29) and years (13). The six birth outcomes are mean birth weight, a dichotomous indicator of birth weight less than 2500 grams (LBW) or less than 1500 grams (VLBW), mean birth weight adjusted for gestational age, a dichotomous indicator for infants that are small for gestational age (SGA), and a dichotomous indicator for low birth weight births born after 36 weeks gestation (Term LBW). All estimates are obtained by ordinary least squares with robust standard errors. 
Table 8. Differences in Birth Outcomes between WIC and non-WIC Participants by Age for Twin Deliveries in New York City 1988-2001 for Women on WIC and/or Medicaid who Initiated Prenatal Care in the First Four Months of Pregnancy

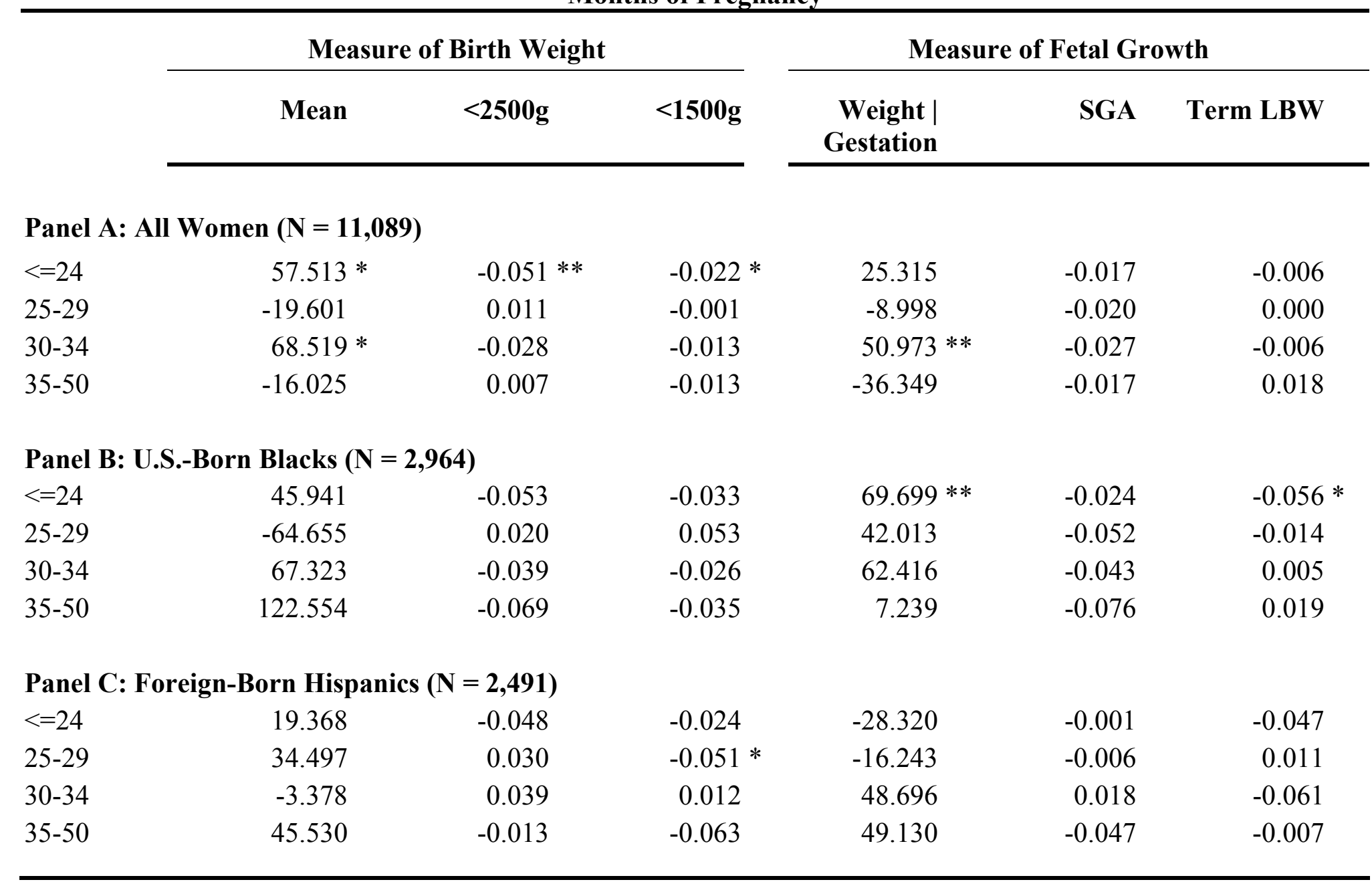

See note to Table 7 


\section{Appendix I}

Table 1A. Characteristics of Twin Births to Women on WIC and/or Medicaid Who Initiated Prenatal Care in the First Four Months of Pregnancy, New York City 1988-2001

\begin{tabular}{|c|c|c|c|c|c|c|c|c|c|}
\hline & \multicolumn{3}{|c|}{ 1988-1990 } & \multicolumn{3}{|c|}{ 1994-1996 } & \multicolumn{3}{|c|}{ 1999-2001 } \\
\hline & Non-WIC & WIC & Diff. & Non-WIC & WIC & Diff. & Non-WIC & WIC & Diff. \\
\hline $\mathrm{N}$ & 782 & 1040 & & 614 & 1896 & & 760 & 2204 & \\
\hline \multicolumn{10}{|l|}{ Measure of birth weight: } \\
\hline Mean & 2270.7 & 2394.0 & $123.3^{* * *}$ & 2365.5 & 2354.4 & -11.11 & 2363.1 & 2326.8 & -36.29 \\
\hline$\%$ LBW $\quad(<2500 \mathrm{~g})$ & 0.565 & 0.517 & $-0.048 * *$ & 0.551 & 0.536 & -0.015 & 0.556 & 0.571 & 0.015 \\
\hline$\%$ VLBW $(<1500 \mathrm{~g})$ & 0.162 & 0.099 & $-0.062 * * *$ & 0.102 & 0.123 & 0.022 & 0.102 & 0.107 & 0.005 \\
\hline \multicolumn{10}{|l|}{ Weeks of gestation: } \\
\hline Mean & 35.624 & 36.246 & $0.622 * * *$ & 35.756 & 35.626 & -0.130 & 35.531 & 35.451 & -0.080 \\
\hline \% Unknown & 0.000 & 0.000 & 0.000 & 0.000 & 0.000 & 0.000 & 0.008 & 0.001 & $-0.007 * * *$ \\
\hline Premature & 0.494 & 0.412 & $-0.082 * * *$ & 0.502 & 0.501 & -0.001 & 0.529 & 0.554 & 0.025 \\
\hline \multicolumn{10}{|l|}{$\begin{array}{l}\text { Measure of fetal growth: } \\
\text { LBW, >36 wks gest }\end{array}$} \\
\hline Small-for-G-A (s) & 0.450 & 0.431 & -0.019 & 0.379 & 0.358 & -0.022 & 0.351 & 0.362 & 0.011 \\
\hline$\%$ Unknown & 0.003 & 0.004 & 0.001 & 0.007 & 0.002 & $-0.004 *$ & 0.013 & 0.003 & $-0.010 * * *$ \\
\hline Small-for-G-A (t) & 0.150 & 0.120 & $-0.029 *$ & 0.132 & 0.098 & $-0.034 * *$ & 0.080 & 0.093 & 0.013 \\
\hline \% Unknown & 0.005 & 0.004 & -0.001 & 0.007 & 0.002 & $-0.004 *$ & 0.013 & 0.003 & $-0.010 * * *$ \\
\hline \multicolumn{10}{|l|}{ Mother's weight-gain: } \\
\hline Mean & 31.874 & 34.231 & $2.357 * *$ & 34.017 & 35.601 & $1.584 * *$ & 38.304 & 36.892 & $-1.413 * *$ \\
\hline \% Unknown & 0.593 & 0.292 & $-0.301 * * *$ & 0.254 & 0.191 & $-0.063 * * *$ & 0.092 & 0.071 & $-0.021 *$ \\
\hline Net weight & 26.774 & 29.045 & $2.271 * *$ & 28.937 & 30.395 & $1.458^{*}$ & 33.160 & 31.786 & $-1.375^{*}$ \\
\hline \multicolumn{10}{|l|}{ Mother's education: } \\
\hline$<12$ years & 0.381 & 0.400 & 0.019 & 0.329 & 0.348 & 0.019 & 0.300 & 0.350 & $0.050 * *$ \\
\hline 12 years & 0.458 & 0.404 & $-0.054 * *$ & 0.391 & 0.430 & $0.040 *$ & 0.387 & 0.389 & 0.002 \\
\hline $13-16$ years & 0.141 & 0.169 & $0.029^{*}$ & 0.235 & 0.186 & $-0.049 * * *$ & 0.258 & 0.224 & $-0.034 *$ \\
\hline$\geq 17$ years & 0.005 & 0.006 & 0.001 & 0.023 & 0.015 & -0.008 & 0.024 & 0.029 & 0.005 \\
\hline Unknown & 0.015 & 0.021 & 0.006 & 0.023 & 0.021 & -0.002 & 0.032 & 0.007 & $-0.024 * * *$ \\
\hline
\end{tabular}


Table 1A. Continued

\begin{tabular}{|c|c|c|c|c|c|c|c|c|c|}
\hline & \multicolumn{3}{|c|}{ 1988-1990 } & \multicolumn{3}{|c|}{ 1994-1996 } & \multicolumn{3}{|c|}{ 1999-2001 } \\
\hline & Non-WIC & WIC & Diff. & Non-WIC & WIC & Diff. & Non-WIC & WIC & Diff. \\
\hline \multicolumn{10}{|l|}{ Mother's age: } \\
\hline $10-19$ & 0.095 & 0.100 & 0.005 & 0.101 & 0.091 & -0.010 & 0.074 & 0.088 & 0.014 \\
\hline $20-34$ & 0.806 & 0.779 & -0.027 & 0.762 & 0.808 & $0.046^{* *}$ & 0.779 & 0.753 & -0.026 \\
\hline $35-50$ & 0.100 & 0.119 & 0.019 & 0.137 & 0.101 & $-0.036^{* *}$ & 0.147 & 0.159 & 0.011 \\
\hline \multicolumn{10}{|l|}{ Mother's race: } \\
\hline Puerto Rican & 0.217 & 0.208 & -0.010 & 0.137 & 0.170 & $0.033^{*}$ & 0.108 & 0.122 & 0.014 \\
\hline Other-Hispanic & 0.199 & 0.200 & 0.001 & 0.221 & 0.276 & $0.055 * * *$ & 0.258 & 0.303 & $0.045^{* *}$ \\
\hline Asian & 0.003 & 0.010 & $0.007 *$ & 0.098 & 0.024 & $-0.073 * * *$ & 0.150 & 0.060 & $-0.090 * * *$ \\
\hline White-Non-Hispanic & 0.097 & 0.077 & -0.020 & 0.189 & 0.081 & $-0.108 * * *$ & 0.184 & 0.077 & $-0.107 * * *$ \\
\hline Black- Non-Hispanic & 0.478 & 0.506 & 0.028 & 0.345 & 0.439 & $0.094 * * *$ & 0.295 & 0.433 & $0.138 * * *$ \\
\hline Other & 0.000 & 0.000 & 0.000 & 0.007 & 0.006 & 0.000 & 0.000 & 0.004 & $0.004 *$ \\
\hline Unknown & 0.005 & 0.000 & $-0.005 * *$ & 0.003 & 0.003 & 0.000 & 0.005 & 0.002 & -0.003 \\
\hline \multicolumn{10}{|l|}{ Marital status: } \\
\hline Single & 0.696 & 0.654 & $-0.042 *$ & 0.635 & 0.700 & $0.065 * * *$ & 0.566 & 0.680 & $0.114^{* * *}$ \\
\hline Unknown & 0.000 & 0.000 & 0.000 & 0.000 & 0.000 & 0.000 & 0.000 & 0.000 & 0.000 \\
\hline \multicolumn{10}{|l|}{ Parity: } \\
\hline First birth & 0.425 & 0.315 & $-0.109 * * *$ & 0.352 & 0.315 & $-0.036^{*}$ & 0.387 & 0.319 & $-0.067 * * *$ \\
\hline \% Unknown & 0.038 & 0.033 & -0.006 & 0.016 & 0.036 & $0.020 * *$ & 0.121 & 0.054 & $-0.067 * * *$ \\
\hline \multicolumn{10}{|l|}{ Mother's birth place: } \\
\hline Foreign born & 0.348 & 0.390 & $0.043^{*}$ & 0.502 & 0.474 & -0.028 & 0.524 & 0.548 & 0.024 \\
\hline \% Unknown & 0.005 & 0.006 & 0.001 & 0.003 & 0.003 & 0.000 & 0.013 & 0.005 & $-0.009 * *$ \\
\hline \multicolumn{10}{|l|}{ Pre-Pregnancy Weight: } \\
\hline Mean & 146.006 & 149.742 & 3.736 & 145.957 & 155.339 & $9.382 * * *$ & 148.317 & 152.994 & $4.677 * * *$ \\
\hline \% Unknown & 0.583 & 0.262 & $-0.322 * * *$ & 0.238 & 0.162 & $-0.075 * * *$ & 0.079 & 0.055 & $-0.024 * *$ \\
\hline \multicolumn{10}{|l|}{ Prenatal doctor visits: } \\
\hline Mean & 9.399 & 10.029 & $0.630 * * *$ & 10.602 & 10.559 & -0.043 & 10.716 & 10.412 & $-0.304 * *$ \\
\hline \% Unknown & 0.020 & 0.012 & -0.009 & 0.010 & 0.036 & $0.026 * * *$ & 0.026 & 0.010 & $-0.016 * * *$ \\
\hline \multicolumn{10}{|l|}{ Drug use d. pregnancy: } \\
\hline Heroin/cocaine & 0.026 & 0.021 & -0.004 & 0.010 & 0.014 & 0.004 & 0.005 & 0.007 & 0.002 \\
\hline \% Unknown & 0.005 & 0.019 & $0.014 * * *$ & 0.016 & 0.033 & $0.016^{* *}$ & 0.003 & 0.000 & $-0.003 * *$ \\
\hline Cigarettes & 0.064 & 0.088 & $0.024^{*}$ & 0.030 & 0.030 & 0.000 & 0.011 & 0.019 & 0.009 \\
\hline
\end{tabular}




\section{Appendix II - Instrumental Variables and Propensity Score Estimates}

We can write our IV model as follows:

$$
\mathrm{G}_{\mathrm{ijt}}=\alpha_{0}+\alpha_{1} \hat{\mathrm{WIC}}_{\mathrm{ijt}}+\mathbf{x}_{\mathrm{ijt}}^{\prime} \boldsymbol{\beta}+\sum y r_{t}+\sum H D_{j}+\mathrm{e}_{\mathrm{jit}}
$$

$$
\begin{aligned}
& \mathrm{WIC}_{\mathrm{ijt}}=\theta_{0}+\mathbf{x}_{\mathrm{ijt}}^{\prime} \gamma+\sum y r_{t}+\sum H D_{j}+\varphi W \hat{I} C_{i j t}+\mathrm{v}_{\mathrm{jit}} \\
& \mathrm{WIC}_{\mathrm{ijt}}=\phi_{0}+\mathbf{x}_{\mathrm{ijt}}^{\prime} \lambda+\sum y r_{t}+\sum H D_{j}+\sum\left(y r_{t} * H D_{j}\right)+\mathrm{v}_{\mathrm{jit}}
\end{aligned}
$$

Continue with the same notation from equation (1) in the text. The new variables, $\mathrm{HD}_{\mathrm{j}}$, are indicators of the woman's health district of residence. New York City is divided into 30 health districts. Our instruments are interactions of year and district (equation 3a). The year dummy pertains to New York State's Medicaid eligibility expansion, which became effective on January 1, 1990. The expansion increased the income eligibility threshold for pregnant women from approximately 100 to 185 percent of the federal poverty level (FPL). Importantly, there was no change in the eligibility criteria for WIC. The income eligibility threshold for WIC was 185 percent of the FPL before and after the Medicaid expansions. ${ }^{10}$ However, as more pregnant women received Medicaid, more were made aware of complementary social services (Joyce 1999). As a result, the expansion in Medicaid appears to have generated a large increase in WIC enrollment. Figure 1A (below) shows the percent of births to women on Medicaid and WIC as well as the percent of births to women on WIC but not Medicaid. As is evident, almost

\footnotetext{
${ }^{10}$ Although income eligibility thresholds are similar, Medicaid's is actually more generous since it refers to net income whereas WIC eligibility is based on gross income.
} 
all the increase in WIC has occurred among women on Medicaid. The percent of births to women on WIC but not Medicaid has remained relatively flat over the entire period.

The second assumption underlying our instrument is that take-up in Medicaid varied with the social service infrastructure of the district. We lack data on the social service infrastructure by health district. As an alternative, we use health district dummies to proxy time-invariant differences between districts. What is clear, however, is that uptake in WIC varied directly with the uptake in Medicaid. As evidence, we regressed the change in the proportion of births on WIC ( $\Delta \% \mathrm{WIC}$ ) by health district on the change in the proportion of births on Medicaid ( $\Delta \% \mathrm{MED}$ ) between 1988-89 and 1991-92 $(\mathrm{n}=30)$. The coefficient on $\triangle \%$ MED was 0.85 with a t-ratio of 3.62. Thus, every one-percentage-point increase in the proportion of women on Medicaid in a health district is associated with a .85 percentage point increase in WIC participation. Thus, New York State's Medicaid eligibility expansion for pregnant women appears to have resulted in a plausibly exogenous increase in prenatal WIC enrollment.

The other less typical aspect of the model in equation (1a)-(3a) is that we use a generated instrument to predict WIC participation instead of the actual instruments. Specifically, we estimate equation (3a) by a probit, predict WIC participation for each individual, and use the predicted values as an instrument for actual participation in equation (2a). The advantage is that the asymptotic properties with the generated instrument are arguably more robust and equation (4) allows for the binary nature of the endogenous variable (Wooldridge 2002). ${ }^{11}$

Finally, we restrict the instrumental variables analysis to births to women on Medicaid between 1988 and 1992. Our purpose is to limit the uptake in WIC to the years in which the change in Medicaid enrollment is arguably more exogenous. We drop women in WIC but not

\footnotetext{
${ }^{11}$ Loosely, we can ignore the fact that predicted WIC in equation (1a) is based on estimated parameters in equation (2a). Moreover, we also do not need the correct functional form for equation (3a) for consistency.
} 
Medicaid because we don't want to confound the two changes. We interpret the instrumental variables estimate as a local average treatment effect (LATE). As such, the estimated gains pertain only to women whose participation in WIC was a result of the Medicaid expansions (Angrist, Imbens and Rubin 1996).

\section{Instrumental Variable Estimates and Propensity Score Matching}

Results from the estimation of equations (1a)-(3a) are displayed in Table 3A. The sample is limited to the years 1988-1992. The first-stage estimates are displayed in Appendix 2A. In Table 3A, we show estimates of average treatment effects obtained by OLS, propensity score matching, and IV for all first births to women on Medicaid or WIC who initiated prenatal care in the first four months of pregnancy. We show the same for the sub-samples of US-born Blacks and foreign-born Hispanics. Regardless of the estimating method, we find no association between WIC participation and fetal growth. In all but a few cases, estimates of average treatment effects obtained by propensity score matching are smaller in absolute value than estimates obtained by OLS, but the differences are not meaningful. The other noteworthy finding is the strikingly different results for birth weight and very low birth weight between USborn Blacks and foreign-born Hispanics. Among US-born Blacks, average treatment effects more than double when estimated by IV, although only one of the four estimates is statistically significant (marginally). Nevertheless, a LATE interpretation of the IV estimates suggests that WIC has a substantial protective effect on birth outcomes among the participants who enrolled as a result of the Medicaid expansions. The opposite occurs among foreign-born Hispanics: the IV estimates reverse sign and are relatively large. Indeed, among foreign-born Hispanics, the 
IV estimates imply that participation in WIC worsens birth outcomes among those who participated as a result of the changes in Medicaid.

We are skeptical that the IV estimates represent causal effects. First, it is unclear why average treatment effects should vary drastically by race, ethnicity and nativity. All the women in our sample are relatively poor, few have any education beyond high school and most are unmarried. Second, the size of the effects among US-born Blacks are an order of magnitude greater than their OLS counterparts, which is not credible given the literature on prenatal nutrition and birth outcomes. One interpretation, therefore, is that the IV exacerbates as opposed to corrects the omitted variable problem. It is not inconceivable that the uptake in Medicaid and WIC is greatest in the health districts in which the decline in crack-cocaine use is the greatest. Second, it is difficult to isolate the effect of WIC in the context of the Medicaid eligibility expansions. Other changes occurred at this time. The State rolled its prenatal care assistance program (PCAP) into Medicaid. PCAP paid greater reimbursement to providers that offered augmented prenatal care services. One such service was nutritional counseling in which WIC enrollment was a measure of compliance. Other services included referrals for substance abuse. Joyce (1999) presents a more detailed analysis of PCAP in New York City. The upshot is that there are potentially several initiatives that may be driving the variation in WIC, which renders interpretation difficult and which undermines exogeneity. 
Appendix II Figure 1. Percent of Births to Women Enrolled in WIC by Medicaid Coverage

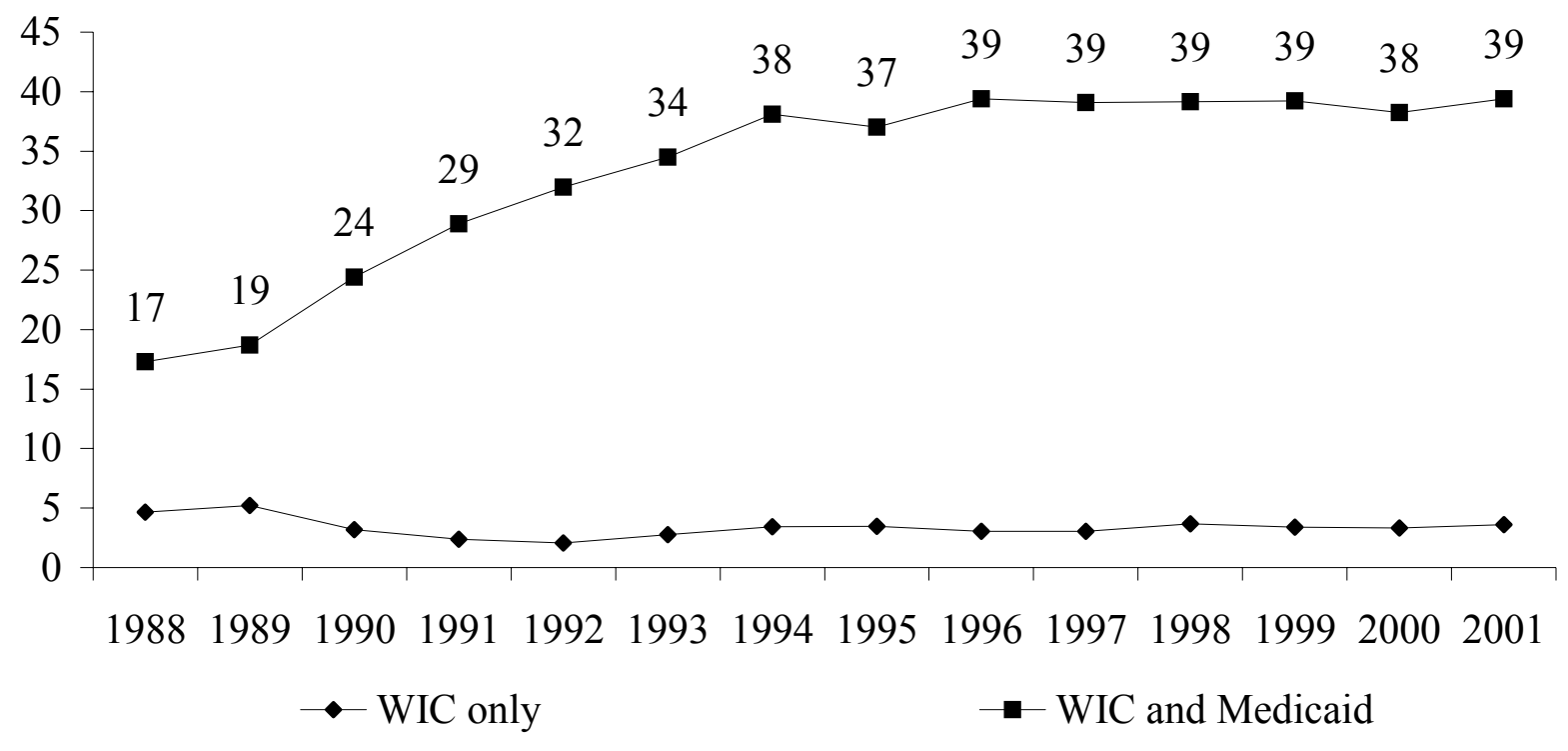


Table 2A. Estimates of First-Stage Probit and OLS with Generated Instrument for all Women.

\section{Dependent variable: WIC participation}

\section{Model: Probit}

Model: OLS

Predicted WIC

$$
1.007 * * *
$$

Mother's education:

12 years
$13-16$ years
$\geq 17$ years
Unknown

Mother's age:

20-34

$35-50$

Unknown

Mother's race:

Puerto Rican

Other-Hispanic

Asian

Black-Non Hispanic

Other

Unknown

Mother's birth place:

Foreign born

Unknown

Marital status:

Single

Drug use during pregnancy:

Heroin/cocaine

Cigarettes

Unknown

Year indicator

Health District

Medicaid $\square$ Health District

$\chi_{(29)}$ Medicaid x Health District

$\begin{array}{cc}-0.026 & 0.000 \\ 0.126 * * * & 0.000 \\ 0.119 * * & 0.000 \\ -0.314 * * * & 0.000\end{array}$

$-0.112 * * *$

0.000

$-0.283 * * *$

0.001

$-0.173$

$-0.005$

$0.445 * * *$

0.000

$0.426 * * *$

$-0.001$

$-0.120$

0.000

$0.422 * * *$

0.000

$1.367 * * *$

$-0.006$

$-0.058$

0.002

$0.156^{* * *}$

0.000

0.118

$-0.002$

$-0.015$

0.000

$-0.249 * * *$

0.000

$0.203 * * *$

0.000

$-0.108 * *$

0.001

Yes

Yes

Yes

Yes

Yes

No

\# The relevant Chi-square (27) for U.S.-born Non-Hispanic Blacks is $=469.35$ and for Foreign-born Hispanics : )

$=1138.36 . * \mathrm{p}<.1 ; * * \mathrm{p}<.05 ; * * * \mathrm{p}<.01$ 
Table 3A. OLS and IV Estimates of Differences in Birth Outcomes between WIC and non-WIC Participants for Singleton Births in New York City 1988-1992 for Women on WIC and/or Medicaid, Who Have No Previous Live Births and Who Initiated Prenatal Care in the first four months of Pregnancy ${ }^{+}$

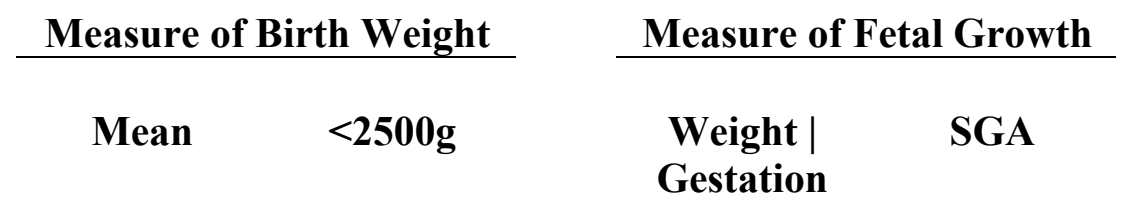

Panel A: All women

\begin{tabular}{|c|c|c|c|c|}
\hline OLS & $\begin{array}{c}26.71 * * \\
(6.92)\end{array}$ & $\begin{array}{c}-0.010 * * \\
(0.003)\end{array}$ & $\begin{array}{c}6.82 \\
(4.78)\end{array}$ & $\begin{array}{c}-0.002 \\
(0.005)\end{array}$ \\
\hline PSCORE $^{+}$ & $\begin{array}{c}22.43 * * \\
(5.03)\end{array}$ & $\begin{array}{c}-0.009 * * \\
(0.003)\end{array}$ & $\begin{array}{c}1.36 \\
(5.10)\end{array}$ & $\begin{array}{c}-0.006 \\
(0.003)\end{array}$ \\
\hline IV & $\begin{array}{c}56.93 \\
(43.08)\end{array}$ & $\begin{array}{c}-0.030 * * \\
(0.011)\end{array}$ & $\begin{array}{c}46.43 \\
(62.69)\end{array}$ & $\begin{array}{l}-0.025 \\
(0.034)\end{array}$ \\
\hline & \multicolumn{4}{|c|}{ Panel B:US-born Blacks } \\
\hline OLS & $\begin{array}{l}57.59 * * \\
(17.88)\end{array}$ & $\begin{array}{c}-0.024 * * \\
(0.009)\end{array}$ & $\begin{array}{c}13.89 \\
(13.75)\end{array}$ & $\begin{array}{c}0.002 \\
(0.009)\end{array}$ \\
\hline PSCORE & $\begin{array}{c}50.25 * * \\
(10.15)\end{array}$ & $\begin{array}{c}-0.024 * * \\
(0.006)\end{array}$ & $\begin{array}{c}12.72 \\
(10.34)\end{array}$ & $\begin{array}{c}-0.005 \\
(0.006)\end{array}$ \\
\hline IV & $\begin{array}{c}163.14 * \\
(76.13)\end{array}$ & $\begin{array}{c}-0.070 * \\
(0.028)\end{array}$ & $\begin{array}{c}112.09 \\
(115.13)\end{array}$ & $\begin{array}{c}-0.053 \\
(0.061)\end{array}$ \\
\hline & \multicolumn{4}{|c|}{ Panel C: Foreign-born Hispanics } \\
\hline OLS & $\begin{array}{l}11.98 \\
(6.58)\end{array}$ & $\begin{array}{l}-0.002 \\
(0.004)\end{array}$ & $\begin{array}{c}5.79 \\
(5.22)\end{array}$ & $\begin{array}{c}-0.004 \\
(0.006)\end{array}$ \\
\hline PSCORE & $\begin{array}{c}1.19 \\
(9.65)\end{array}$ & $\begin{array}{c}0.000 \\
(0.004)\end{array}$ & $\begin{array}{l}-7.62 \\
(9.76)\end{array}$ & $\begin{array}{c}-0.003 \\
(0.006)\end{array}$ \\
\hline IV & $\begin{array}{l}-58.60 \\
(39.28)\end{array}$ & $\begin{array}{c}0.041 \\
(0.026)\end{array}$ & $\begin{array}{l}-19.62 \\
(45.80)\end{array}$ & $\begin{array}{c}0.034 \\
(0.037)\end{array}$ \\
\hline
\end{tabular}

\footnotetext{
${ }^{+}$The sample is limited to women on Medicaid and or WIC who delivered a live birth between 1988 and 1992. PSCORE refers to estimates obtained by propensity score matching based on the nearest neighbor algorithm (see Becker and Ichino 2002). Note that the following variables are not balanced in the analysis of all women (Panel A): marital status, high school education, black non-Hispanic See equations (2)-(4) in the text for a description of the IV model. The list of covariates is described in the footnote to Table 4. Standard errors in OLS and IV regressions have been adjusted for cluster at the health district level.
} 